\title{
AMPA Receptor Phosphorylation and Synaptic Colocalization on Motor Neurons Drive Maladaptive Plasticity below Complete Spinal Cord Injury
}

\author{
ㄱ. J. Russell Huie, ${ }^{1}$ Ellen D. Stuck, ${ }^{1}{ }^{\circledR}$ Kuan H. Lee, ${ }^{2}$ Karen-Amanda Irvine, ${ }^{1,3}$ - Michael S. Beattie, ${ }^{1}$ \\ Jacqueline C. Bresnahan, ${ }^{1}$ (D) James W. Grau, ${ }^{4}$ and Adam R. Ferguson ${ }^{1,3}$
}

\section{DOI:http://dx.doi.org/10.1523/ENEURO.0091-15.2015}

${ }^{1}$ Department of Neurological Surgery, Brain and Spinal Injury Center, University of California San Francisco, San Francisco, California 94110, ${ }^{2}$ Department of Neurobiology, University of Pittsburgh, Pittsburgh, Pennsylvania 15261, ${ }^{3}$ San Francisco Veterans Affairs Medical Center, San Francisco, California 94121, and ${ }^{4}$ Department of Psychology, Texas A\&M University, College Station, Texas 77841

\begin{abstract}
Clinical spinal cord injury (SCl) is accompanied by comorbid peripheral injury in $47 \%$ of patients. Human and animal modeling data have shown that painful peripheral injuries undermine long-term recovery of locomotion through unknown mechanisms. Peripheral nociceptive stimuli induce maladaptive synaptic plasticity in dorsal horn sensory systems through AMPA receptor (AMPAR) phosphorylation and trafficking to synapses. Here we test whether ventral horn motor neurons in rats demonstrate similar experience-dependent maladaptive plasticity below a complete $\mathrm{SCl}$ in vivo. Quantitative biochemistry demonstrated that intermittent nociceptive stimulation (INS) rapidly and selectively increases AMPAR subunit GluA1 serine 831 phosphorylation and localization to synapses in the injured spinal cord, while reducing synaptic GluA2. These changes predict motor dysfunction in the absence of cell death signaling, suggesting an opportunity for therapeutic reversal. Automated confocal time-course analysis of lumbar ventral horn motor neurons confirmed a time-dependent increase in synaptic GluA1 with concurrent decrease in synaptic GluA2. Optical fractionation of neuronal plasma membranes revealed GluA2 removal from extrasynaptic sites on motor neurons early after INS followed by removal from synapses $2 \mathrm{~h}$ later. As GluA2-lacking AMPARs are canonical calcium-permeable AMPARs (CP-AMPARs), their stimulus- and time-dependent insertion provides a therapeutic target for limiting calcium-dependent dynamic maladaptive plasticity after SCl. Confirming this, a selective CP-AMPAR antagonist protected against INS-induced maladaptive spinal plasticity, restoring adaptive motor responses on a sensorimotor spinal training task. These findings highlight the critical involvement of AMPARs in experience-dependent spinal cord plasticity after injury and provide a pharmacologically targetable synaptic mechanism by which early postinjury experience shapes motor plasticity.
\end{abstract}

Key words: AMPA receptor; motor neuron; nociception; plasticity; spinal cord injury; spinal learning

\section{Significance Statement}

Recent findings have demonstrated that painful stimuli below a spinal cord injury can affect future locomotor training and recovery in spinal cord injured patients (Bouffard et al., 2014), as well as in animal models (Ferguson et al., 2008a; Ferguson et al., 2012a; Ferguson et al., 2012b). However, the cellular and molecular mechanisms for this experience-dependent modulation of spinal cord plasticity are poorly understood. This work uncovers a novel synaptic mechanism by which peripheral nociceptive (painful) input following a spinal cord injury can undermine future adaptive spinal cord plasticity, providing a novel target for improving recovery after spinal cord injury, and mitigating aberrant forms of spinal neuroplasticity. 


\section{Introduction}

In the human spinal cord injury (SCl) population there is a high incidence of concomitant peripheral injury, including lacerations, abrasions, and fractured limbs (Saboe et al., 1991; Sekhon and Fehlings, 2001; Wang et al., 2001; Hasler et al., 2011). Although these injuries may be considered minor in comparison to the $\mathrm{SCl}$, the nociceptive input to the spinal cord produced by these peripheral injuries may have a lasting effect on recovery of sensory and motor function. A large body of preclinical work has demonstrated that peripheral nociceptive input produces lasting alterations in dorsal horn neurons through cellular mechanisms similar to those underlying hippocampal learning and memory (Sandkühler and Liu, 1998; Ikeda, 2006). These spinal cord "pain memory" signatures have been suggested to underlie pain disorders, such as hyperalgesia and neuropathic pain (Ji et al., 2003; Sandkühler, 2009; Ruscheweyh et al., 2011; Drdla-Schutting et al., 2012).

Peripheral nociceptive input affects not only dorsal pain pathways, but also spinal motor systems. Peripheral intermittent nociceptive stimulation (INS) below a SCI produces nociceptive hyper-reflexia, acute deficits in adaptive spinal motor learning, and lasting ( $>6$ weeks) impairment in recovery of locomotor function (Grau et al., 1998, 2004,2012; Garraway et al., 2011, 2014; Huie et al., 2012b). Such findings suggest that the injured spinal cord is highly vulnerable to peripheral sensory input, with a heightened capacity for the spinal motor systems to encode maladaptive forms of synaptic plasticity. The clinical relevance of peripherally-induced spinal cord maladaptive plasticity was highlighted by a recent clinical study demonstrating that brief peripheral nociceptive input undermines the ability of human $\mathrm{SCl}$ patients to retain locomotor learning tasks (Bouffard et al., 2014).

Although a growing body of work has sought to determine the neural mechanisms underlying maladaptive plasticity in pain pathways, it is unknown whether nociception-induced alterations in motor circuits reflect

Received August 17, 2015; accepted October 5, 2015; First published October 30, 2015.

The authors report no conflict of interest.

Contributions: J.R.H., K.-A.I., M.S.B., J.C.B., J.W.G., and A.R.F. designed research; J.R.H., E.D.S., K.H.L., and K.-A.I. performed research; J.R.H., E.D.S., K.H.L., J.W.G., and A.R.F. analyzed data; J.R.H. wrote the initial draft, J.R.H., A.R.F., M.S.B., J.C.B. and J.W.G. wrote and revised the paper.

This work was supported by NIH Grants NS069537, NS088475, NS067092 to A.R.F., NS038079 to M.S.B. and J.C.B., NS041548 to J.W.G., the Craig H. Neilsen Foundation, and the Wings for Life Foundation. We thank Drs Jessica Nielson, Ernesto Salegio, Sangmi Lee, Aiwen Liu, and Cristian Guandique for comments on an earlier version of this paper, and Dr Kurt Thorn and the staff at the Nikon Imaging Center at UCSF for assistance with all confocal image collection.

Correspondence should be addressed to Adam R. Ferguson, Brain and Spinal Injury Center, University of California San Francisco, 1001 Potrero Avenue, Building 1, Room 101, San Francisco, CA 94110. E-mail: adam.ferguson@ucsf.edu.

DOI:http://dx.doi.org/10.1523/ENEURO.0091-15.2015

Copyright (C) 2015 Huie et al.

This is an open-access article distributed under the terms of the Creative Commons Attribution 4.0 International, which permits unrestricted use, distribution and reproduction in any medium provided that the original work is properly attributed. these same processes. One key aspect of spinal cord pain plasticity is the postsynaptic alteration of fastexcitatory glutamate AMPA receptors (AMPARs; Hartmann et al., 2004; Galan et al., 2004). Recent work has also highlighted the specific role of AMPAR subunit phosphorylation site serine 831 in encoding activity-dependent spinal cord pain memory traces in dorsal spinal neurons following peripheral stimulation (Drdla-Schutting et al., 2012).

It has been recently shown that $\mathrm{SCl}$ specifically increases postsynaptic localization of GluA2-lacking, calcium-permeable AMPA receptors (CP-AMPARs) on motor neurons (Ferguson et al., 2008b). In addition, AMPAR activity impacts spinal cord motor training, suggesting potential for dynamic modulation of AMPARs in spinal cord motor systems (Hoy et al., 2013). The synaptic insertion and activation of CP-AMPARs are crucial to the induction of synaptic plasticity and homeostatic scaling in CNS neurons in vitro (Man, 2011; Garcia-Bereguiain et al., 2013). CP-AMPARs are normally highly regulated, and are trafficked out of synaptic sites; however, under pathophysiologic conditions, CP-AMPAR activity may be dysregulated and sustained, overdriving excitation and ultimately inducing cell death (Kuner et al., 2005; von Lewinski and Keller, 2005; Liu et al., 2006; Ferguson et al., 2008b; Oh et al., 2012; Spaethling et al., 2012; Dias et al., 2013).

Given these prior findings, we hypothesized that nociceptive input induces maladaptive spinal cord plasticity by overdriving CP-AMPARs in motor neurons in the injured spinal cord. We applied a well established peripheral nociceptive stimulation procedure to induce maladaptive motor plasticity, and tested for AMPAR and downstream signaling changes by quantitative biochemistry, robotic confocal image analysis, and behavioral assessments at acute time-points following complete $\mathrm{SCl}$. The results uncovered a time dependent overdrive of CP-AMPARs that was independent of cell death and pharmacologically targetable to reset spinal cord plasticity below SCl.

\section{Materials and Methods}

\section{Animals}

Male Sprague-Dawley rats (Harlan), aged 100-120 d were housed individually and had ad libitum access to food and water $(N=64)$. All procedures were conducted in accordance with the National Institute of Health Guide for the Care and Use of Laboratory Animals, and all efforts were made to minimize suffering and limit the number of animals used. All protocols were approved by the University Laboratory Animal Care Committee at Texas A\&M University.

\section{Experimental methodology}

In all experiments, experimenters were kept blind to treatment conditions throughout the entire study in accordance with recent quality standards for preclinical neurological research (Landis et al., 2012). Western blot loading order was determined a priori by a third-party coder who insured that a representative sample from each condition was included on each gel in a randomized 
block design. For each experiment, the number of subjects per condition was kept consistent across groups to insure proper counterbalancing could be achieved across independent Western runs. All representative Western images presented in the figures represent lanes from the same gel. Because of our randomized counterbalancing scheme, occasionally the critical comparisons of interest were not available on adjacent lanes (but do come from the same gel). The entire set of randomized Western blot images are available upon request. Confocal image acquisition and subsequent data analyses were also performed by experimenters blind to treatment condition.

\section{Spinal transection surgery}

All animal subjects received a complete transection of the spinal cord immediately rostral to the second thoracic vertebra (T2). Animals were fully anesthetized with isoflurane gas (5\%). Fur over the thoracic vertebra was shaved, and a $3 \mathrm{~cm}$ incision was made over T2. The tissue immediately rostral to T2 was cleared away with rongeurs, and the underlying spinal cord was exposed. An electrical heat cautery device was used to transect the spinal cord and the resulting cavity was filled with gelfoam (Harvard Apparatus). The incision was then closed using Michel clips (Fine Science Tools). Animals received a $2.5 \mathrm{ml}$ intraperitoneal injection of $0.9 \%$ saline immediately following surgery, and twice daily for subsequent days to ensure proper hydration. Bladders were expressed twice daily. Given the nociceptive nature of this study, no analgesics were given following complete spinal transection.

\section{Intermittent nociceptive stimulation}

Twenty-four hours after complete spinal transection surgery, animals were placed in black Plexiglas tubes, $22 \mathrm{~cm}$ in length and $6.8 \mathrm{~cm}$ in diameter. The tail was allowed to hang freely from the end of the tube, and an electrode coated in ECG gel was fixed to the tail $\sim 6 \mathrm{~cm}$ from the base of the tail using orthaletic tape. Constant-current 1.5 $\mathrm{mA}, \mathrm{AC}$ stimulation was delivered to the electrode using a $660 \mathrm{~V}$ transformer. Stimulation delivery was controlled by computer program, with each pulse $80 \mathrm{~ms}$ in duration delivered intermittently over $6 \mathrm{~min}$, on a variable interstimulus interval (range 0.2-3.8 s; mean $2 \mathrm{~s}$ ). This schedule resulted in a total of $\sim 180$ stimulation presentations. Each animal received either a single 6 min stimulation session, or an equivalent period of unstimulated restraint with the electrodes attached.

\section{Western blot}

Animals were deeply anesthetized with pentobarbital (100 $\mathrm{mg} / \mathrm{kg}$, i.p.), decapitated, and spinal cords were harvested by rapid fluid expulsion with ice-cold phosphatebuffered saline (PBS) at $20 \mathrm{~min}, 2 \mathrm{~h}$, or $24 \mathrm{~h}$ following nociceptive stimulation. Spinal cords were immediately flash-frozen in liquid nitrogen, and then transferred to $-80^{\circ} \mathrm{C}$. The entire surgical procedure was timed to ensure time from decapitation to snap freeze was $<5 \mathrm{~min}$.

Fresh-frozen spinal cords were subsequently rapidly thawed on a chilled petri dish at $4^{\circ} \mathrm{C}$, and a $1 \mathrm{~cm}$ section of the lumbar enlargement was dissected. This section was then split once along the midline, followed by a cut to separate the dorsal and ventral quadrants (Fig. 1A). A single quadrant containing the ventral horn was then placed in a Dounce homogenizer filled with $200 \mu \mathrm{m}$ homogenization buffer (10 mM Tris, $30 \mathrm{~mm}$ sucrose, $\mathrm{pH} 7.5$ ) containing phosphatase and protease inhibitors (Roche). Following tissue disruption, the whole homogenate was placed in an Eppendorf tube, and spun at 5000 relative centrifugal force (rcf) for $5 \mathrm{~min}$ in a minicentrifuge at $4^{\circ} \mathrm{C}$. This centrifugation procedure produced a supernatant (S1) and a nuclear pellet (P1). The S1 layer was removed and centrifuged a second time at 13,000 rcf for $30 \mathrm{~min}$ at $4^{\circ} \mathrm{C}$, producing a modestly synaptoneurosomal-enriched pellet fraction (P2) that was subsequently used in Western blots (Fig. 1B; Galan et al., 2004; Ferguson et al., 2008b; Stück et al., 2012). Total protein concentration was quantified using the Pierce BCA protein assay method. Each sample was then diluted 1:2 in room temperature Laemmli sample buffer, and $20 \mu \mathrm{g}$ of total protein per sample was loaded into separate lanes on a precast $10-20 \%$ electrophoresis gel (Tris- $\mathrm{HCl}$ polyacrylamide, BioRad). Samples were counterbalanced across the gel by treatment condition, and the experimenter was kept blind to condition. A kaleidoscope ladder was loaded on each gel to confirm molecular weight. The gel was electrophoresed for $1 \mathrm{~h}$ at $100 \mathrm{~V}$ in SDS buffer $(25 \mathrm{~mm}$ Tris, $192 \mathrm{~mm}$ glycine, 0.1\% SDS, pH 8.3; BioRad). Protein was transferred to a nitrocellulose membrane in cold transfer buffer $(25 \mathrm{~mm}$ Tris, $192 \mathrm{~mm}$ glycine, $20 \%$ methanol, pH 8.3). The membrane was blocked for $1 \mathrm{~h}$ in Odyssey Blocking Buffer (LiCor) containing $0.1 \%$ Tween 20 , followed by an overnight incubation in primary antibody solution at $4^{\circ} \mathrm{C}$. Primary antibody solution consisted of rabbit polyclonal antiphosphorylated serine 831 (1:200; Millipore), in Odyssey blocking buffer plus $0.05 \%$ Tween 20 . Following incubation, the membrane was washed $4 \times 5$ min with Trisbuffered saline containing $0.1 \%$ Tween 20 (TTBS) and incubated in fluorescent-labeled secondary antibody (1: $30 \mathrm{~K}$ LiCor IRdye 680 goat anti-rabbit in Odyssey blocking buffer plus $0.2 \%$ Tween 20 ) for $1 \mathrm{~h}$ in the dark. Subsequent to $4 \times 5$ min washes in TTBS, followed by a $5 \mathrm{~min}$ wash in TBS. The membrane was immediately scanned on the LiCor Odyssey Infrared Imaging System with a 680 $\mathrm{nm}$ laser to reveal protein bands. The membrane was then re-blocked and reincubated with mouse anti-GluA1 primary antibody (1:200, Millipore) in Odyssey blocking buffer plus $0.05 \%$ Tween 20 . The membrane was then washed as before, and incubated in fluorescent-labeled secondary antibody (1:30K LiCor IRdye 800 goat antimouse in Odyssey blocking buffer plus $0.2 \%$ Tween 20 ), washed as before, and rescanned with the $800 \mathrm{~nm}$ laser to reveal GluA1 protein bands. This same protocol was performed for serine 845 on GluA1, GluA2, and Serine 880 on GluA2. Loading controls were performed as the last step on each multiplexed Western blot. Cell death marker assays (cFos, cJun, calpain I, and cleaved caspase, 1:250; Cell Signaling Technologies), were performed on a separate set of gels that were performed on cytosolic (S2) fractions. Otherwise, the Western blot protocols for cell death markers were identical to those used for AMPAR assays. 


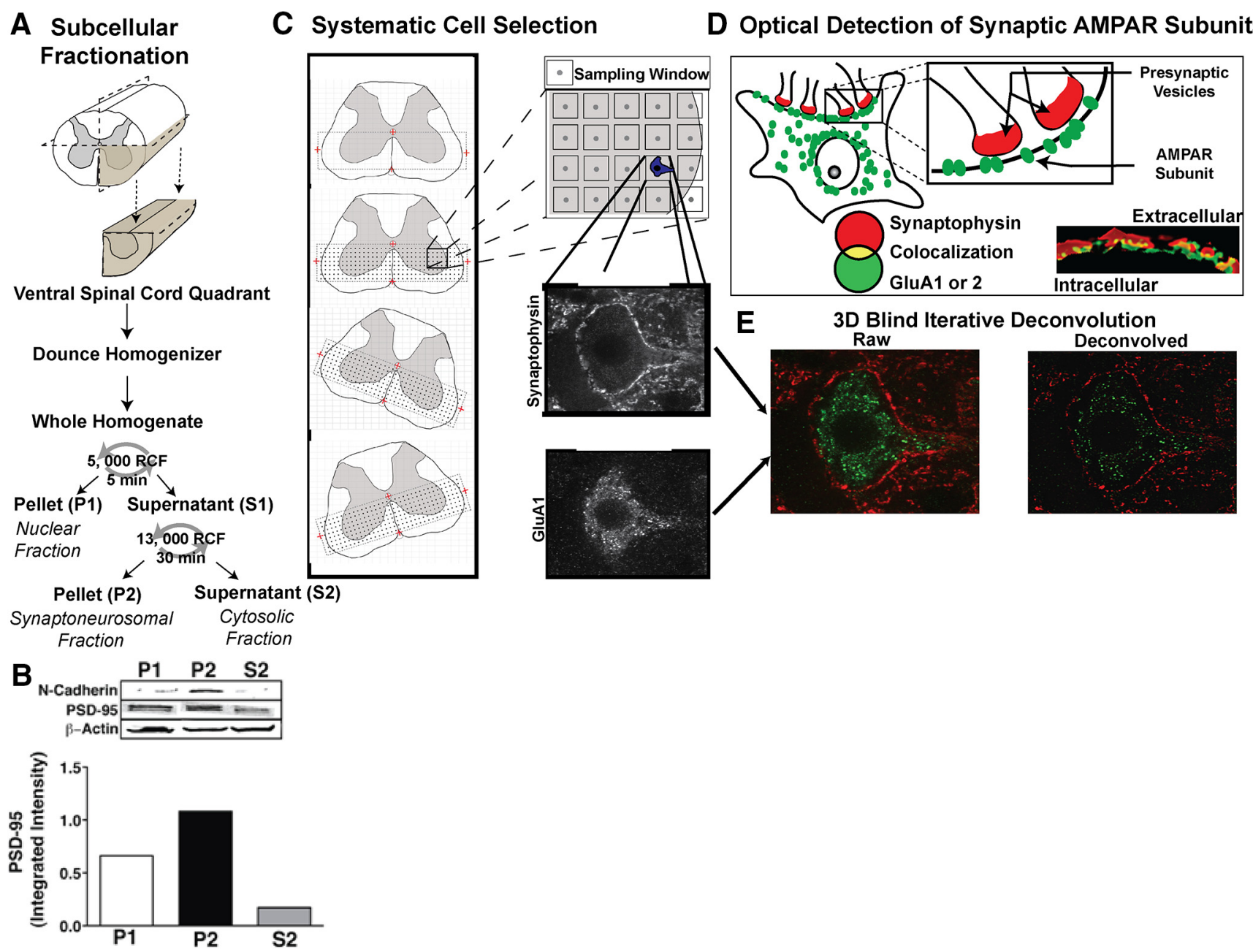

Figure 1. Subcellular fractionation of ventral lumbar spinal cord. $A$, Ventral quadrant of lumbar spinal cord tissue was dissected and homogenized using a Dounce homogenizer. The whole homogenate was then centrifuged for 5 min at 5000 rcf, and the supernatant (S1) was removed. This S1 fraction was then centrifuged for 30 min at 13,000 rcf. The pellet from this fraction (P2) was then used for all subsequent Western blots. $\boldsymbol{B}$, Plasma membrane enrichment in the P2 fraction was confirmed with $N$-cadherin expression, and modest synaptic enrichment (synaptoneurosome) was characterized by PSD-95, with beta-actin serving as loading control. $\boldsymbol{C}$, Tissue-oriented coordinate grid placement for systematic cell selection. Large ventral horn neurons were systematically selected from spinal cord slices in L4-L5 region. A microscopist blind to experimental condition entered the stage coordinate location of four anatomical landmarks (central canal, anterior artery, left edge of tissue, right edge of tissue) into an Excel spreadsheet, and a custom VisualBasic macro generated a list of microscope stage coordinates that were then input into MicroManager and ImageJ software that controlled microscope stage movement. This system ensured that the orientation of the coordinate grid would always be relative to the specific orientation of the tissue. Each coordinate signified the center of an $80 \times 80 \mu \mathrm{m}$ sampling window, with each coordinate spaced $100 \mu \mathrm{m}$ apart. The blind microscopist cycled through these sampling windows at $63 \times$. When a large neuron (cell body $>40$ $\mu \mathrm{m}$ ) was encountered within a sampling window, the cell was centered in the frame and a stack of images was taken through the z-plane, with separate images taken through a $650 \mathrm{~nm}$ filter (for synaptophysin) and a $490 \mathrm{~nm}$ filter (for GluA1 or GluA2) at each level. $\boldsymbol{D}$, Optical detection of synaptic AMPAR subunits. Yellow pixels produced by the overlapping of the presynaptic marker synaptophysin (red) and postsynaptic AMPAR subunit (green) puncta indicated colocalization and were quantified to determine the amount of synaptic AMPAR subunit expression. $\boldsymbol{E}$, All image stacks were combined and deconvolved to correct for the diffusion of light using AutoQuant software.

To ensure accurate protein quantification, we used protein dilution curves for each primary antibody to detect the linear range in which fluorescence was most highly correlated with changes in protein concentration using Odyssey Application Software v3.0. The optimal dilution and laser intensity at which protein concentration and fluorescence yielded the greatest linear correlation was established separately for each antibody and then held constant for the duration of the experiment (all $R^{2}>0.98$ ). Fluorescence for each band was quantified using Odyssey software and normalized to median pixel density of background fluorescence.

\section{Immunohistochemistry}

Animals ( $n=4$ per group) underwent intracardial perfusion under deep $(100 \mathrm{mg} / \mathrm{kg})$ pentobarbital anesthesia, 
either 20 min or $2 \mathrm{~h}$ post-INS. Animals were perfused first with ice cold PBS, followed by $4 \%$ paraformaldehyde to fix tissue. The spinal cord was excised and postfixed overnight $(<18 \mathrm{~h})$ in $4 \%$ paraformaldehyde then cryoprotected in $30 \%$ sucrose for $2 \mathrm{~d}$. The tissue was embedded in OCT within $10 \mathrm{~mm}$ blocks, flash frozen on dry ice, and sectioned into $20-\mu \mathrm{m}$-thick coronal slices.

The L4-L5 region of the spinal cord was identified anatomically using Luxol Fast Blue (LFB) staining. The tissue was dried for $1 \mathrm{~h}$ and hydrated with 1:1 95\% ethanol to chloroform for $4 \mathrm{~h}$. Slides were incubated in a solution of $0.1 \%$ LFB for $18 \mathrm{~h}$ at $56^{\circ} \mathrm{C}$. The tissue was then washed in water and the LFB stain was differentiated by a 20 s $0.1 \%$ lithium carbonate wash. The tissue was washed again with water. Tissue was soaked in 95\% ethanol for $2 \mathrm{~min}, 100 \%$ ethanol for $5 \mathrm{~min}$, and another bath of $100 \%$ ethanol for $5 \mathrm{~min}$. Slides were coverslipped with DPX mounting medium.

Four fixed-tissue sections from the L4-L5 region of the spinal cord from each subject were antibody-labeled using a high-throughput staining station (Sequenza; Thermo Scientific). Tissue was blocked and permeabilized with $5 \%$ normal goat serum and $0.3 \%$ Triton $\mathrm{X}-100$ for $1 \mathrm{~h}$ and incubated overnight at room temperature in primary antibody solution consisting of mouse monoclonal antipresynaptic synaptophysin (1:200; Millipore) and either rabbit monoclonal antibody against GluA1 (1:200; Upstate) or rabbit polyclonal antibody against GluA2 (1:200; Chemicon). Slides were washed $2 \times 5$ min with $2 \mathrm{ml} \mathrm{PBS}$ then incubated for $1 \mathrm{~h}$ at room temperature in a secondary solution containing 1:100 AlexaFluor 488 goat anti-rabbit and 1:100 AlexaFluor 633 goat anti-mouse secondary antibodies. Slides were washed $2 \times 5$ min with $2 \mathrm{ml}$ PBS, and then coverslipped with Vectashield containing DAPI (4', 6-diamidino-2-phenylindole; Vector Laboratories). AMPAR GluA1 and GluA2 subunits were assessed on adjacent slide sets from the same subjects.

\section{Robotic confocal microscopy sampling and deconvolution}

A Nikon spinning disk confocal microscope $(63 \times$ objective; $\mathrm{NA}=1.4 ; 2 \times$ zoom) was used to collect confocal images of large ventral neurons. To systematically sample motor neurons, a custom Visual Basic program was used to automatically overlay a sampling grid on the ventral half of each spinal section, aligned to the central canal and ventral artery as fiduciary points. This grid contained $90 \times$ $90 \mu \mathrm{m}$ sampling windows that were spaced $100 \mu \mathrm{m}$ apart both horizontally and vertically (Fig. 1C). Large neurons were identified based on the distinctive synaptophysin outline surrounding the plasma membrane and characterized by a cell body diameter $>40 \mu \mathrm{m}$ (Fig. 1C). A microscopist blind to condition used ImageJ software (v1.47, $\mathrm{NIH}$ ) on the confocal microscope to advance through each sampling window, and gathered confocal images of neurons if they were encountered in the sampling window. If a sampling window contained multiple neurons, a single neuron was chosen at random. Control tissue was used to optimize filter and laser settings, which were then held constant throughout the experiment. Confocal z-stacks consisted of slices collected at $0.25 \mu \mathrm{m}$ z-intervals. Confocal stacks were batch deblurred off-line using 3-D blind iterative deconvolution (AutoQuant; Fig. 1E). Based on a random subset of images an experimentally blind rater determined the number of iterations for the deconvolution algorithm to yield maximal resolution for each antibody (iteration $=4$ for GluA1; iteration $=2$ for GluA2). Once selected a priori, iteration numbers were held constant throughout the experiment. A total of 539 cells were assessed for GluA1, and 484 cells were assessed for GluA2. A total of 23,723 optical planes were analyzed, with an average number of 23 optical planes per cell.

We used automated image analysis to quantify the number of fluorescently labeled AMPAR puncta that exceeded a predetermined pixel threshold that was based on control tissue. Automated image analysis was performed using custom-designed MetaMorph (Molecular Devices) macros. One macro quantified AMPAR puncta at the level of the neuropil. This macro measured the amount of total AMPAR pixels as well as colocalized synaptophysin and AMPAR pixels in each plane of the z-stack. Another macro quantified fluorescently labeled AMPAR puncta on the plasma membrane of motor neurons. This macro first identified the plane in the $z$-series with the highest amount of synaptophysin and AMPAR subunit (GluA1 or GluA2) synaptic colocalization. The automated plane selection was monitored by a blinded researcher to prevent selection based on staining artifacts. A blinded researcher traced the synaptophysin labeled plasma membrane of the motor neuron on a single optical plane. The macro then generated a $2-\mu \mathrm{m}$-thick cutout containing the plasma membrane "optical fraction" of the cell from the single plane. From the plasma membrane containing cutout, MetaMorph quantified total AMPAR subunit pixels and colocalized AMPAR pixels with synaptophysin pixels (Fig. 1D).

\section{Intrathecal drug delivery}

To inhibit CP-AMPAR activity, the specific antagonist Naspm (Sigma-Aldrich) was delivered intrathecally. A subset of animals ( $n=12$ per group) were fitted with an intrathecal cannula at the time of spinal transection. The $25 \mathrm{~cm}$ cannula was threaded into the subarachnoid space at the second thoracic vertebra, and slid $9 \mathrm{~cm}$ caudally so that the tip of the cannula rested on the dorsal surface of the L4-L5 section of the spinal cord. Immediately following nociceptive stimulation, a $10 \mu \mathrm{l}$ Hamilton syringe was fitted onto the exposed end of the cannula, and $10 \mu \mathrm{l}$ of either Naspm (10 mm) or saline vehicle was delivered over the $3 \mathrm{~min}$. This injection was followed by a $20 \mu \mathrm{l}$ flush with saline, and the exposed end of the cannula was then heat-sealed.

\section{Spinal sensorimotor task}

Testing of spinal learning was conducted $24 \mathrm{~h}$ after complete spinal transection. Animals were loosely restrained in black Plexiglas tubes $(22 \mathrm{~cm}$ in length $\times 6.8 \mathrm{~cm}$ in diameter). To limit the effects of trunk movement on hindlimb position while in the tube, a wire belt was wrapped around the animal's trunk. Hindlimbs were allowed to hang freely from the tube. One hindlimb was shaved, and a wire electrode was inserted through the 


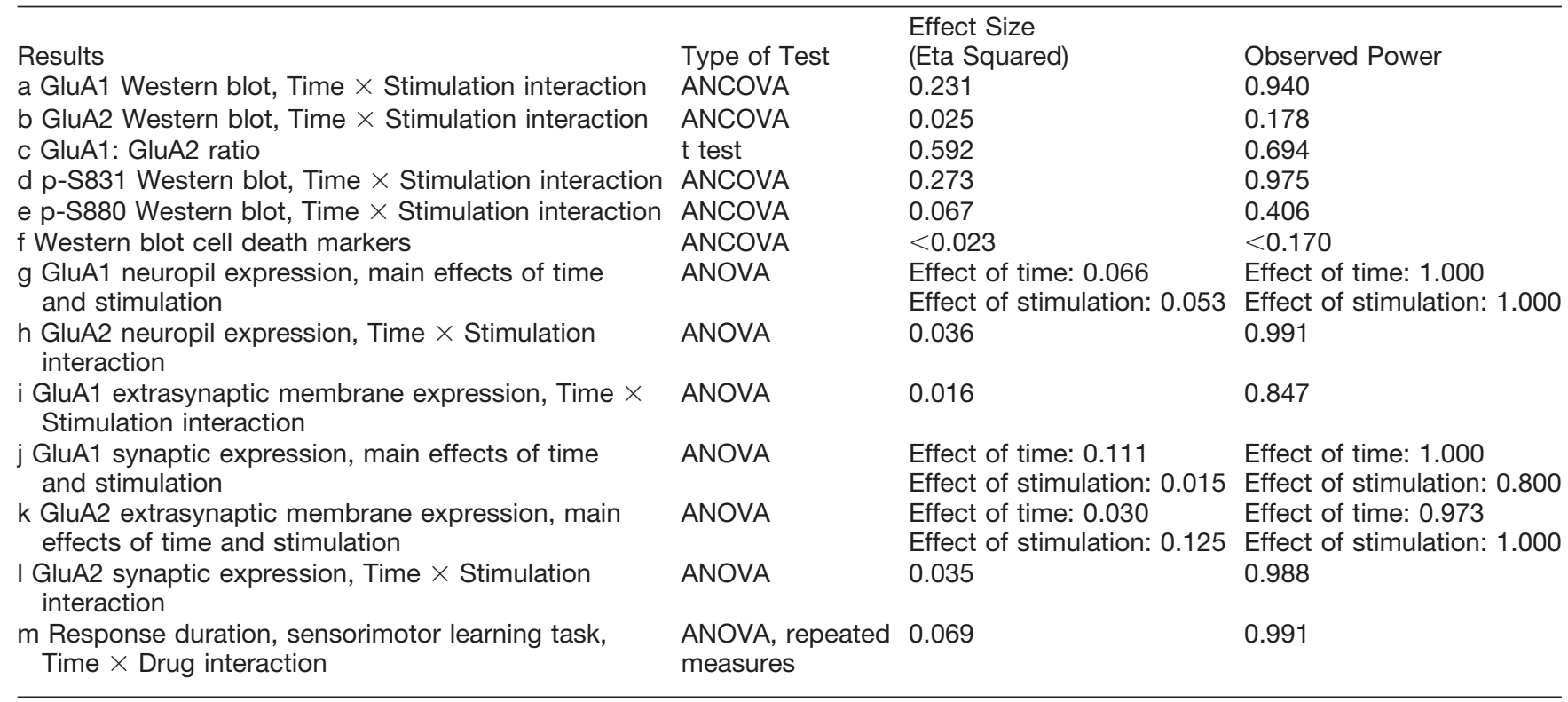

skin over the ankle, distal to the tibialis anterior muscle. A second electrode was inserted into the body of the tibialis anterior muscle, $\sim 1.7 \mathrm{~cm}$ from the first electrode. This second electrode was connected to a wire running to a BRS/LVE constant current shock generator $(60 \mathrm{~Hz}, \mathrm{AC})$. A stainless steel contact electrode $(7 \mathrm{~cm}$ in length, $0.46 \mathrm{~cm}$ in diameter) was secured to the hindpaw between the second and third digits with a piece of porous orthaletic tape. A wire extending from the contact electrode was connected to a computer-monitored digital input. Prior to testing, intensity of the stimulation was adjusted for each animal so that a 0.4 $\mathrm{N}$ force in flexion was elicited. Force was recorded by attaching a monofilament plastic line around the animal's hindpaw, and running this line to a strain gauge (Fort-1000, World Precision Instruments). This strain gauge was connected to a multimeter calibrated to convert a change in voltage to force in Newtons. Brief $(300 \mathrm{~ms})$ shock pulses were then delivered to the anterior tibialis muscle, and the force of ankle flexion was recorded. Intensity was then adjusted until a $0.4 \mathrm{~N}$ force in flexion was achieved. After the intensity of stimulation was determined to elicit a $0.4 \mathrm{~N}$ flexion, the monofilament line was removed.

A rectangular plastic dish containing a salt solution was positioned $7.5 \mathrm{~cm}$ below the restraining tube. The level of salt solution was adjusted so that the contact electrode that extended from the rat's hindpaw was submerged 4 $\mathrm{mm}$ in the solution. A stainless steel rod $(1 \mathrm{~mm}$ in diameter) connected to a ground wire was then placed in the salt solution and the computer-controlled 30 min testing session was started. Whenever the contact electrode was submerged in the salt solution, a circuit was completed, the state of which was relayed to the stimulator, and stimulation was delivered to the tibialis anterior. Whenever the contact electrode was raised from the salt solution, the stimulation was terminated.

Three behavioral measures were taken during the testing session: time in solution, response number, and re- sponse duration. The computer monitoring the state of the circuit recorded the total amount of time that the contact electrode was in the salt solution for each $1 \mathrm{~min}$ time bin. Each time the contact electrode was lifted from the salt solution, response number was increased. Response duration was calculated from time in solution and response number according to the equation: Response Duration $_{i}=\left(60 \mathrm{~s}-\right.$ Time in Solution $\left._{i}\right) /($ Response Number $+1)$, where $i$ is the current 1 min time bin.

\section{Statistical analyses}

Statistical analyses were performed using SPSS Statistics (v.20, IBM). Parametric Western blot data for each experiment were pooled across three independent replications and covariance corrected by beta-actin loading control, with replication statistically controlled as a random factor. A mixed-model analysis of covariance (ANCOVA; with betaactin loading control as covariate) was used to test for main effects and interactions between time and stimulation condition. Tests of main effects were followed by planned pairwise comparisons of control/experimental group estimated marginal means at each timepoint (least significant difference). Confocal and behavioral data were assessed by ANOVA, followed by Tukey's post hoc tests of group means. Ratio data were analyzed with Student's $t$ test, followed by Mann-Whitney $U$ to rule out nonparametric effects. Significance was assessed at $p<0.05$. Power and effect sizes for analyses can be found in Table 1, and referred to by superscript letters throughout the results section.

\section{Results}

\section{INS drives GluA1 but not GluA2 subunits into synaptoneurosomes in a time-dependent fashion}

To assess the role of AMPAR activity in maladaptive spinal plasticity we applied an INS procedure (Fig. 2A) that induces maladaptive behavioral effects, including nociceptive hyper-reactivity, impaired spinal cord motor 
A

Complete Spinal Transection at T2

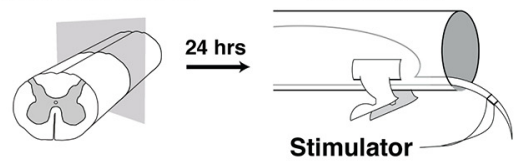

B

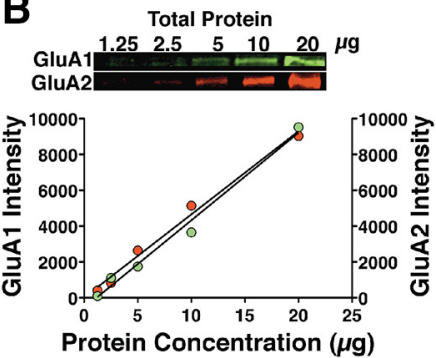

20 MINUTES POST-STIMULATION
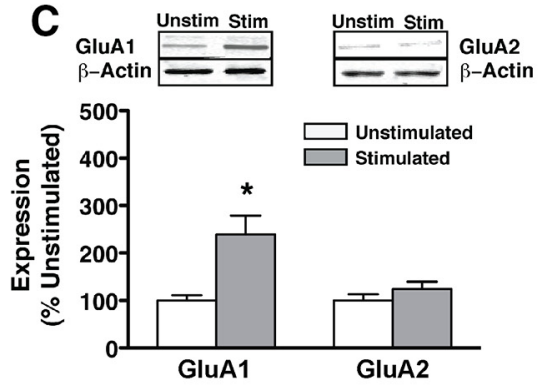

E
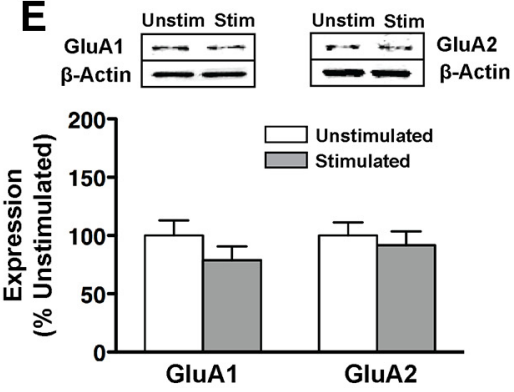

D

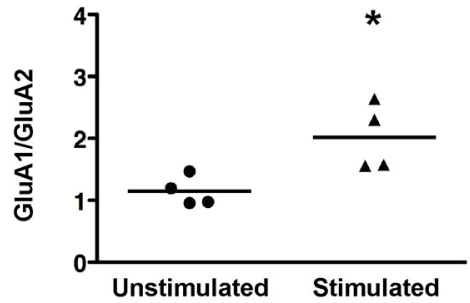

2 HOURS POST-STIMULATION
$\mathbf{F}$
$\mathbf{G}$

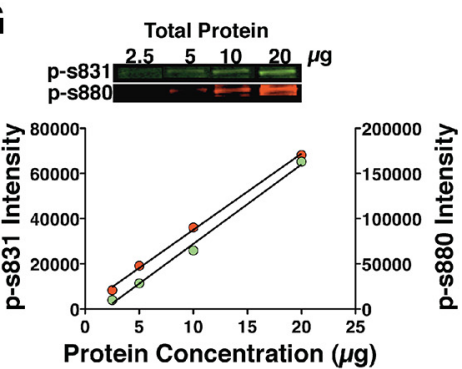

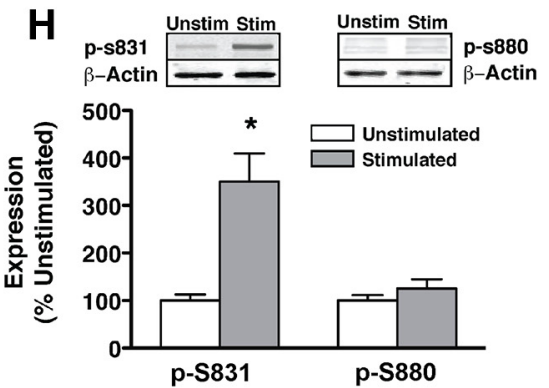

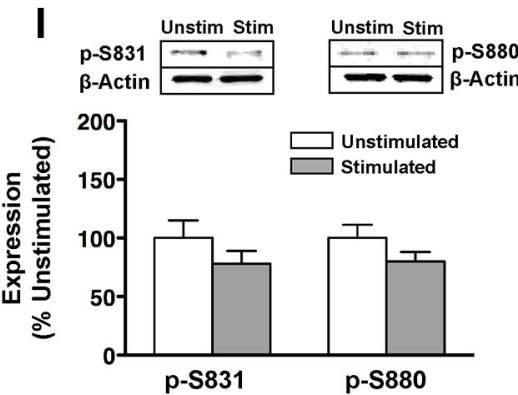

Figure 2. Plasma membrane GluA1 and GluA2 phosphorylation with intermittent nociceptive stimulation delivered below complete spinal cord injury. A, Intermittent nociceptive stimulation. Rats with complete spinal transections received 6 min of intermittent nociceptive stimulation to the tail. Unstimulated controls received an equivalent period of restraint. B, Quantitative fluorescent intensity optimized for linear detection of each target band using a 1:2 dilution curve of total protein. Laser scanning intensity for each target protein was chosen based on closest linear relationship between fluorescent intensity and total protein (all $R^{2}>0.98$ ). All subsequent analyses for each target protein were run at their respective optimal scanning intensities to ensure linearity of fluorescence (see Materials and Methods for details). C, Linear quantification of GluA1 and GluA2 AMPAR subunits, 20 min poststimulation. Stimulation significantly increased GluA1 expression compared to unstimulated controls $(* p<0.05)$, whereas GluA2 expression was unchanged. $\boldsymbol{D}$, The ratio of GluA1 to GluA2 subunit expression was significantly increased in stimulated animals within 20 min (Mann-Whitney $U ; * p<0.05$ ). $\boldsymbol{E}, \boldsymbol{F}$, Linear quantification of GluA1 and GluA2 AMPAR subunits, 2 h poststimulation. Stimulation had no significant effect on GluA1 or GluA2 after 2 h $(p>0.05)$. G, Linear intensity optimization on phosphorylated serines 831 and 880. $\boldsymbol{H}$, Linear quantification of p-S831 and p-S880 protein expression 20 min poststimulation. Stimulation significantly increased phosphorylated serine 831 expression relative to unstimulated controls $(* p<0.05)$, whereas phosphorylated serine 880 was unchanged. I, Stimulation had no significant effect on p-S831 or pS880 after $2 \mathrm{~h}(p>0.05)$. All bars represent mean for $n=4$ subjects/per group ( $n=8$ for main effects, $n=4$ for interaction) with three independent Western blot runs per subject. Error bars represent standard error of the mean.

training, and impaired recovery of function after $\mathrm{SCl}$ (Crown et al., 2002b; Grau et al., 2004; Ferguson et al., 2006), and measured AMPAR changes within lumbar spinal cord synaptoneuromes by quantitative near-IR Western blotting (Fig. 2B). Time-series data indicated that INS increases GluA1 subunit localization to synaptic fraction by 20 min with no change in GluA2 (Fig. 2C). ANCOVA (with beta-actin as covariate) revealed a significant Time $\times$ Stimulation interaction for GluA1 $\left(F_{(1,43)}=13.10^{\mathrm{a}}, p<\right.$
$0.05)$, but not GluA2 $\left(F_{(1,43)}=1.12^{\mathrm{b}}, p>0.05\right)$. A Student's $t$ test revealed a significant increase in the GluA1/GluA2 ratio at 20 min post-INS (Fig. $2 D ; p<0.05^{\circ}$ ). A MannWhitney $U$ test was also used to rule out any nonparametric effects, and this test confirmed the $t$ test result. These effects resolved by $2 \mathrm{~h}$ poststimulation (Fig. 2E,F). Pairwise comparisons at each time point revealed a significant increase in GluA1 in stimulated animals at 20 $\min$ (Fig. $2 C ; p<0.05$ ), but not at $2 \mathrm{~h}$ (Fig. $2 E ; p>0.05$ ). 
In contrast, there was no significant pairwise effect of stimulation on GluA2 at either time point (Fig. 2C,E; $p>$ $0.05)$. Together the results suggest that INS drives GluA2-lacking AMPARs into synapses in the ventral spinal cord in a time-dependent fashion.

\section{Serine 831 phosphorylation of synaptic GluA1 in the injured spinal cord}

Given that GluA2-lacking AMPARs are calcium permeable (Hollmann et al., 1991), the current study provide a potential mechanism for prior findings that INS engages calcium-dependent kinases, protein kinase $C$ (PKC), and calcium-calmodulin-dependent kinase II (CaMKII; Baumbauer et al., 2007; Ferguson et al., 2008a; Huie et al., 2012a). PKC and CamKII modulate ongoing AMPAR activity by phosphorylating serine 831 (p-S831) on GluA1 and serine 880 (p-880) GluA2 (Roche et al., 1996; Matsuda et al., 1999). Quantitative phospho-Western blot of these targets revealed that INS transiently increased p-S831 on GluA 1 by 20 min resolving by $2 \mathrm{~h}$ (Fig. $2 H, I)$. No change was observed in p-S880 on GluA2 (Fig. $3 H, I)$. ANCOVA (beta-actin covariate) confirmed Time $\times$ Stimulation interaction for GluA1 p-S831 $\left(F_{(1,43)}=16.10^{\mathrm{d}}, p<\right.$ $0.05)$, but no effect for GluA2 p-S880 $\left(F_{(1,43)}=3.10^{\mathrm{e}}, p>\right.$ 0.05). Pairwise comparisons at each time point confirmed a significant increase in p-S831 at 20 min (Fig. 3H; $p<$ 0.05 ) but not 2 h (Fig. 3/; p>0.05). As with GluA2, p-S880 expression was not affected by stimulation at either time point $(p>0.05)$. We also found no significant effect of time or stimulation on phosphorylated serine 845 , the PKA binding site for GluA1 ( $p>0.05$, data not shown). The phospho-assay results confirm a selective and timedependent increase in GluA1 p-S831, a known gain-offunction modification of GluA1 conferred by PKC and CaMKII (Roche et al., 1996; Lee et al., 2000). Together with the subcellular localization data, the results suggests that nociceptive stimulation increases neural excitability in two ways: (1) by increasing GluA2-lacking localization to synaptic sites, and (2) by increasing the function of these inserted AMPARs through PKC/CamKII-phosphorylation (Ferguson et al., 2006; Hook et al. 2008).

\section{Nociceptive stimulation below $\mathrm{SCl}$ does not induce acute cell death in lumbar ventral horns}

GluA2-lacking AMPARs have previously been shown to contribute to cell death of large motor neurons in the SCI lesion penumbra, leading us to ask whether INS modulates cell death in an experience-dependent fashion. We ran a panel of biomarkers for proteins associated with increased cellular activity, excitotoxicity, and/or apoptotic cell death (Fig. 3). Cytosolic subcellular fractions of ventral lumbar spinal homogenates were assessed for cFos, cJun, calpain I, and cleaved caspase 3 at $20 \mathrm{~min}, 2 \mathrm{~h}$, or $24 \mathrm{~h}$ after stimulation. Despite a trend toward an early increase in cFos and cJun (Fig. $3 A$ ), and a later increase in calpain I and caspase 3 (Fig. 3B), ANCOVA (with betaactin as covariate) revealed no significant effect of stimulation on any of these biomarkers $\left(F_{(1,65)}<0.53^{f}, p>\right.$ $0.05)$. These findings confirm that the synaptic effects observed in synaptoneurosomes were not likely from a small sample of cells that had survived a stimulation- induced cell death event. These findings also raise the possibility that the maladaptive effects of nociceptive input may be reversible.

\section{Nociceptive stimulation below $\mathrm{SCl}$ increases synaptic GluA1 and decreases synaptic GluA2 in the ventral horn neuropil in a time-dependent manner} The observed synaptoneuromal changes in GluA1/GluA2 suggest a broad shift in total synaptic content toward a GluA2-lacking AMPAR profile; however, biochemical methods do not provide resolution at a single-cell level to assess whether these changes occur within a uniform population of cells to impact excitability. To test for GluA1/GluA2 ratio shifts in a well-phenotyped neuronal population of clinical significance, we targeted large motor neurons in the ventral horn. This was accomplished using a blinded, randomized analytical workflow of automated robotic high-resolution spinning disk confocal microscopy, followed by 3D blind iterative deconvolution, and automated image analysis to explicitly quantify synaptic and extrasynaptic AMPAR puncta on large ventral horn neurons and surrounding dendritic fields (Fig. 1). Large-scale analysis of $>90,000$ confocal images of large ventral motor neurons revealed a significant timedependent increase in GluA1 puncta colocalized to synaptophysin-labeled synapses in INS-treated subjects relative to unstimulated controls (Fig. 4A,B). ANOVA confirmed main effects of stimulation and time for synaptic GluA1 $\left(F_{(1,536)}>30.20^{9}, p<0.01\right.$ and a significant Time $\times$ Stimulation effect for synaptic GluA2 $\left(F_{(1,493)}=18.62^{\mathrm{h}} ; p\right.$ $<0.01)$. Pairwise comparisons revealed that INS significantly increased synaptic GluA1 by 20 min poststimulation $(p<0.05)$, whereas GluA2 levels remained unchanged (Fig. $4 E, p>0.05)$. At $2 \mathrm{~h}$ poststimulation, synaptic GluA1 expression remained elevated, whereas synaptic GluA2 was significantly diminished (Fig. $4 F ; p<0.05$ ). The decrease in GluA2 between 20 min and $2 \mathrm{~h}$ after nociceptive stimulation suggests turnover of AMPAR subtypes from a calciumimpermeable GluA2-containing population to calciumpermeable GluA2-lacking AMPARs.

\section{Nociceptive stimulation decreases GluA2 expression first at extrasynaptic sites, then at synaptic sites on ventral horn neurons in vivo}

Cell culture work has demonstrated activity-dependent AMPARs trafficking occurs in distinct phases. First, AMPARs are trafficked from intracellular endosomes into extrasynaptic plasma membrane. They are then moved laterally into the synapse by means of a distinct molecular mechanism (Borgdorff and Choquet, 2002; Park et al. 2004). We sought to determine whether in vivo INS engages distinct time-dependent changes in extrasynaptic and synaptic distribution of GluA1 and GluA2 in the injured spinal cord. Using custom designed automated image analysis macros, we narrowed the focus of analysis to the plasma membrane compartment of lumbar ventral spinal motor neurons to assess the localization of GluA1 or GluA2 at extrasynaptic and synaptic sites (Fig. $5 A-L$ ). Automated analysis of a single optical plane (algorithmically-selected) from $>2400$ motor neurons revealed changes in GluA1 that were tightly cou- 


\section{A 20 MINUTES POST-STIMULATION}

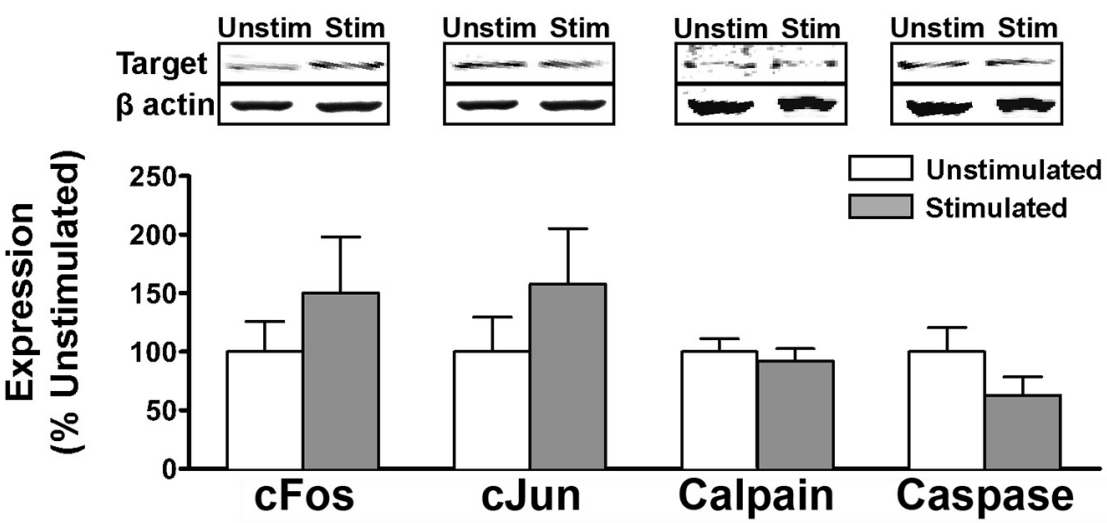

B
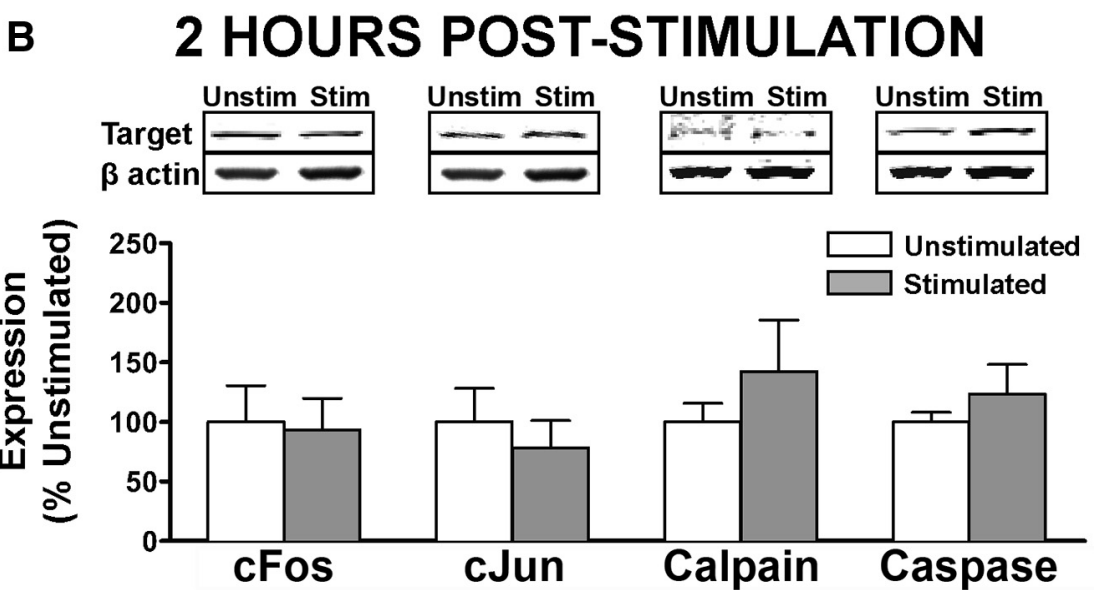

C $\quad 24$ HOURS POST-STIMULATION

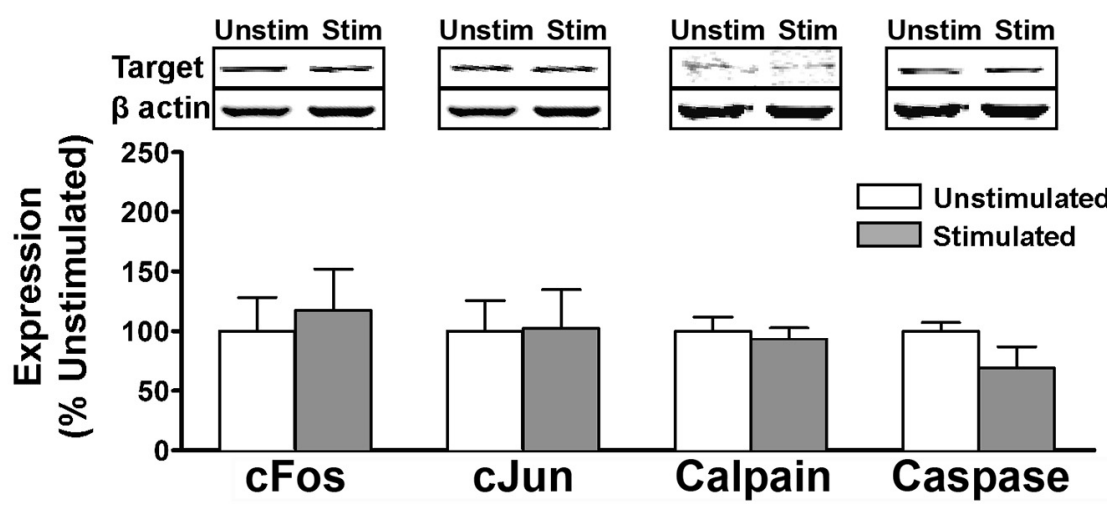

Figure 3. Assessment of neuronal activity and cell death markers following nociceptive stimulation. Linear Western blot quantification of cell activity and death in cytosolic fractions of ventral lumbar spinal cord, assessed at (A) $20 \mathrm{~m}$, (B) $2 \mathrm{~h}$, or $(\boldsymbol{C}) 24 \mathrm{~h}$ after intermittent nociceptive stimulation. ANOVA showed no significant increase in broad neuronal activity marker cFos, in other more specific markers of apoptotic cell death (cJun, cleaved caspase3) or in calcium-mediated cell death (calpain I). No significant differences were observed for beta-actin loading control $(p>0.05)$. Bars represent mean for $n=4$ subjects/factorial group $(n=12$ for INS main effect; $n=8$ for time main effect; $n=4$ for interaction) with three independent Western blot runs per subject. Error bars represent standard error of the mean.

pled between extrasynaptic and synaptic sites, whereas GluA2 showed distinct temporal features at extrasynaptic and synaptic sites, resulting in a net increase in GluA1GluA2 ratio (Fig. $5 A-L)$, but through distinct mechanisms at different time points. At extrasynaptic sites, GluA1 rapidly increased and GluA2 decreased by 20 min postINS (Fig. 5M). However, at synaptic sites only GluA1 increases were seen, with no change in GluA2 (Fig. $5 N$ ). 
UNSTIMULATED
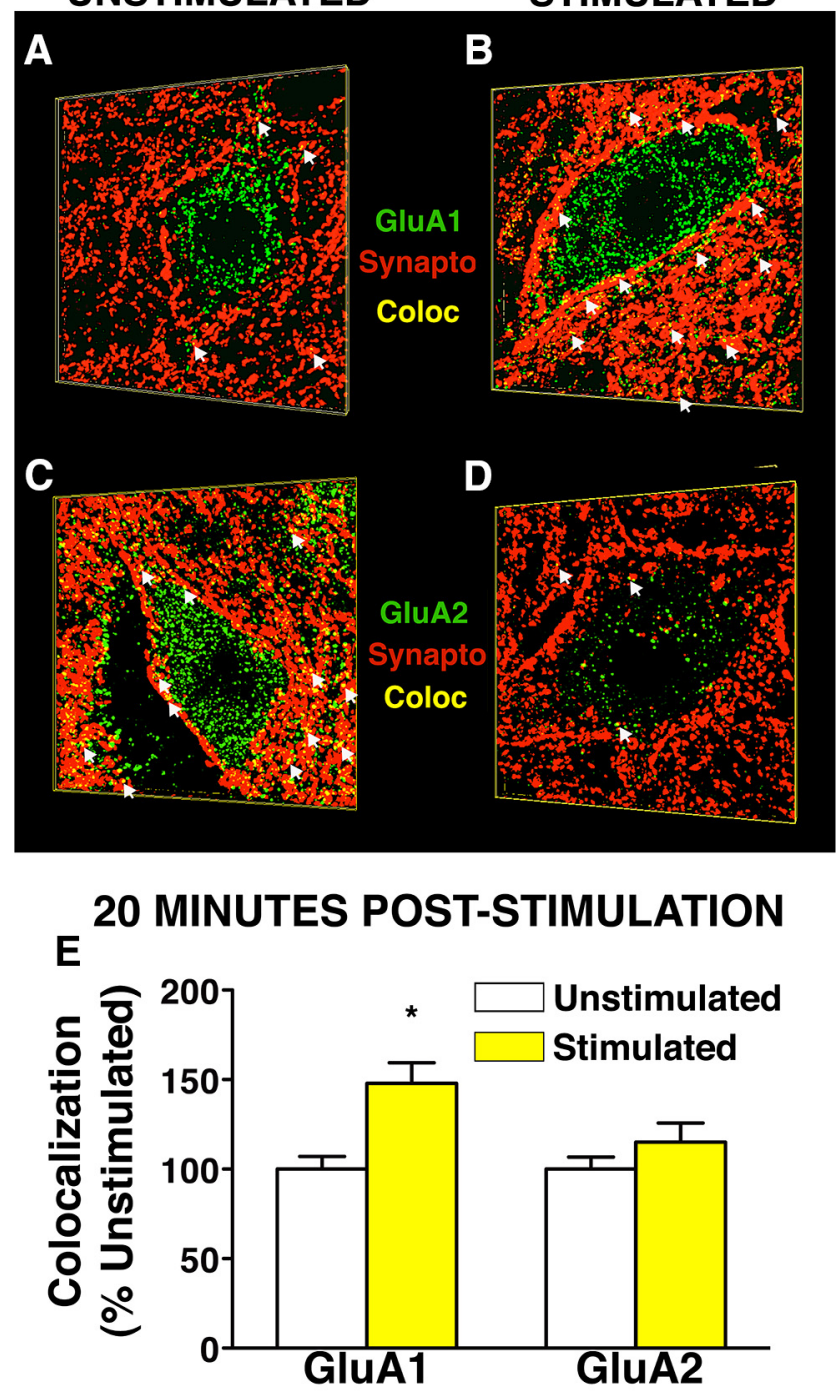

2 HOURS POST-STIMULATION

$\mathbf{F}$

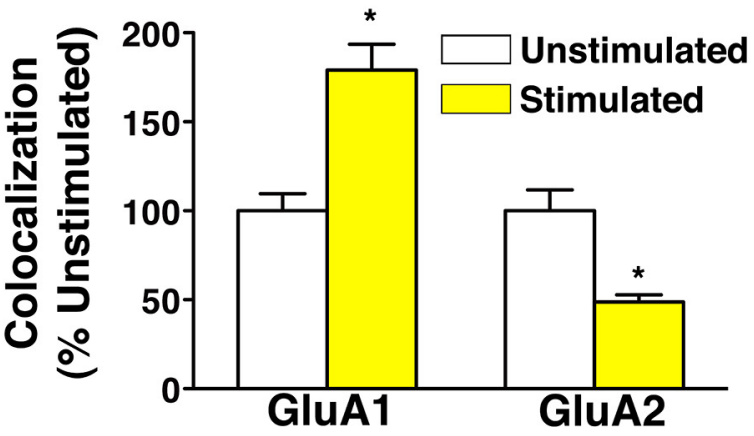

Figure 4. Synaptic GluA1 and GluA2 expression in 3-D synaptic field surrounding ventral horn neurons after intermittent nociceptive stimulation below complete spinal cord injury. Large ventral horn neurons in the L4-L5 region were assessed for colocalization of GluA1/2 (green) to synaptophysin-positive synapses (red) in nociceptive-stimulated and unstimulated spinally transected animals. $\boldsymbol{A}-\boldsymbol{D}$, Representative 3-D confocal images of ventral horn neurons $2 \mathrm{~h}$ after stimulation or control demonstrating an increase in GluA1 expression (A, B, green), and decreased GluA2

\section{Figure 4. continued}

expression (C, $\boldsymbol{D}$, green) after stimulation. Scale bar, $30 \mu \mathrm{m}$. $\boldsymbol{E}$, Quantification of GluA1 and GluA2 through confocal stacks at 20 min poststimulation shows a significant increase in synaptic GluA1 $(* p<0.05)$ and no change in GluA2. $\boldsymbol{F}$, Quantification of GluA1 and GluA2 through confocal stacks at $2 \mathrm{~h}$ poststimulation shows a significant increase in synaptic GluA1 and a concomitant decrease in synaptic GluA2 $(* p<0.05)$. Bars represent mean colocalization through confocal $z$-series of ventral horn neurons (124-146 cells per group assessed for GluA1, 105-154 cells per group assessed for GluA2; $n=4$ subjects/per group; $N$ $=16$ rats total). Error bars represent standard error of the mean.

By $2 \mathrm{~h}$ poststimulation persistent GluA2 removal was observed at both extrasynaptic and synaptic sites, whereas GluA1 changes returned to control levels (Fig. $50, P)$. An ANOVA confirmed a significant Time $\times$ Stimulation interaction on GluA1 expression at extrasynaptic sites $\left(F_{(1,535)}=8.94^{i}, p<0.01\right)$ and main effects of time and stimulation at synaptic sites $\left(F_{(1.534)}>7.88^{\mathrm{j}} ; p<\right.$ $0.01)$. Pairwise comparisons revealed that stimulation significantly increased extrasynaptic and synaptic GluA1 at 20 min $(p<0.05)$, and that these effects waned by 2 h ( $p$ $>0.05)$. Analysis of GluA2 revealed significant main effects of time and condition at extrasynaptic sites $\left(F_{(1,493)}\right.$ $\left.>15.16^{\mathrm{k}}, p<0.01\right)$, and a significant Time $\times$ Stimulation interaction on synaptic GluA2 $\left(F_{(1,493)}=17.93^{\prime}, p<0.01\right)$. Pairwise comparisons revealed that INS significantly decreased extrasynaptic GluA2 20 min after stimulation (Fig. $6 M ; p<0.01$ ), followed by a similar decrease in both extrasynaptic and synaptic GluA2 expression by $2 \mathrm{~h}$ after stimulation (Fig. 5O,P; $p<0.01$ ). These findings suggest that INS-induced maladaptive plasticity in the injured spinal cord may reflect an increased membrane expression of GluA2 lacking-AMPARs that is initiated extrasynaptically, and then expressed at synaptic sites by $2 \mathrm{~h}$ following stimulation. This has potential implications for timing of therapeutic interventions to reduce motor neuron hyperexcitability after $\mathrm{SCl}$.

\section{Specific CP-AMPAR antagonist restores spinal motor training capacity in the face of nociceptive stimulation below a complete $\mathrm{SCl}$}

To assess behavioral consequences and therapeutic targeting of CP-AMPAR activity in INS-induced spinal plasticity we harnessed a behavioral assay of adaptive sensorimotor modification in the spinal cord (Grau et al., 1998, 2006). INS is known to impair spinal cord sensorimotor training and recovery of locomotor function after SCl (Crown et al., 2002a; Grau et al., 2004). To test whether CP-AMPAR over-activity mediates the INSinduced deficits in motor function, we intrathecally delivered a specific CP-AMPAR antagonist (Naspm) following INS and then tested spinal cord sensorimotor training capacity using a spinal instrumental (response-outcome) learning task. The spinal training assay requires rats with complete T2 spinal cord transection to increase the duration of hind-limb flexion (ie, the response) to reduce exposure to nociceptive electric shock (outcome; Fig. 6A). Given that the lumbar spinal cord is surgically isolated 
GluA1 Synapto Colloc
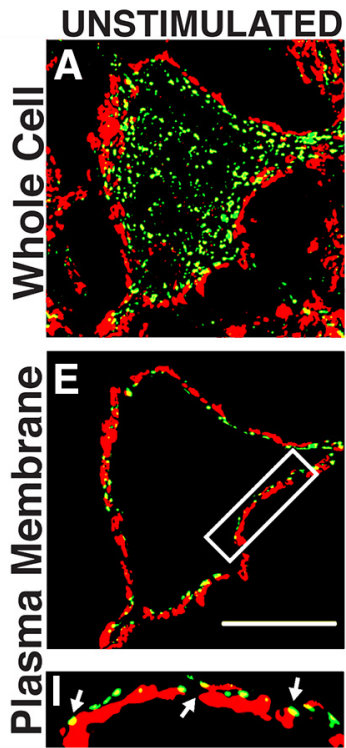

STIMULATED
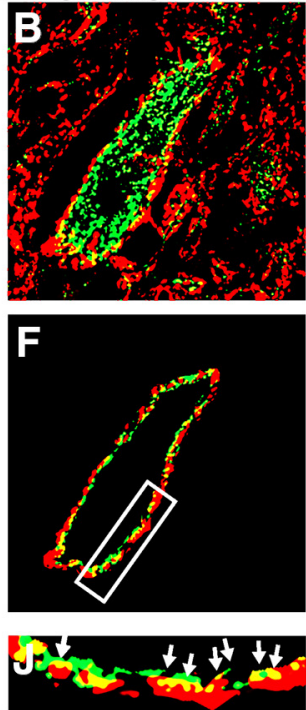
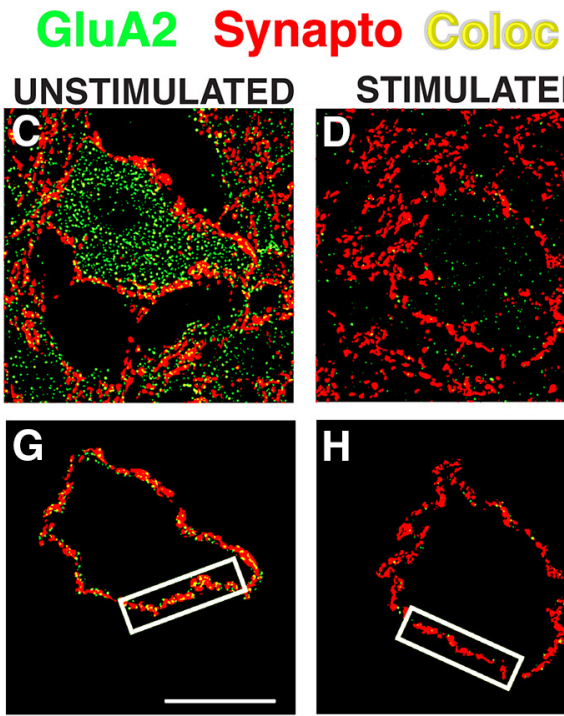

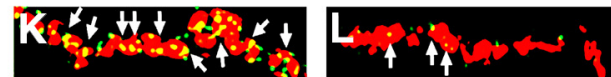

20 MINUTES POST-STIMULATION

M

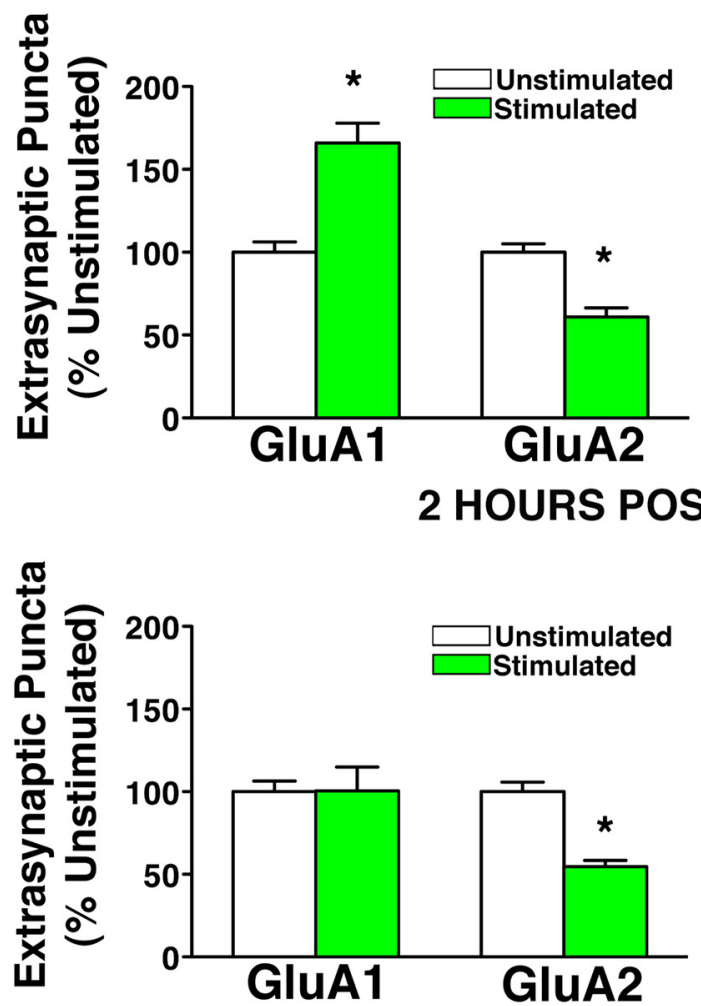

$\mathrm{N}$

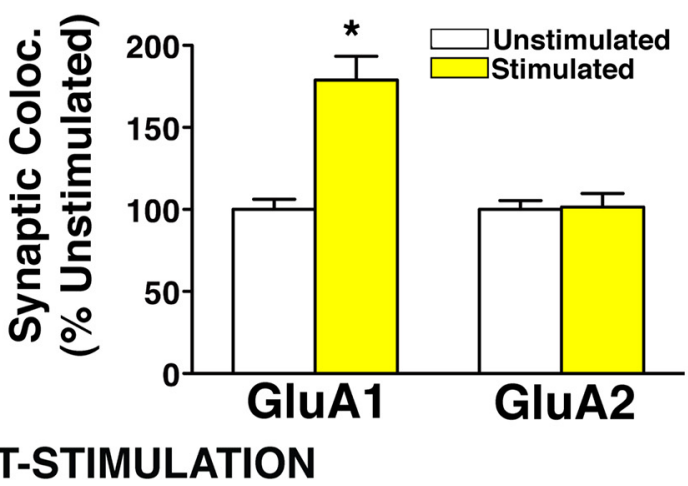

$P$
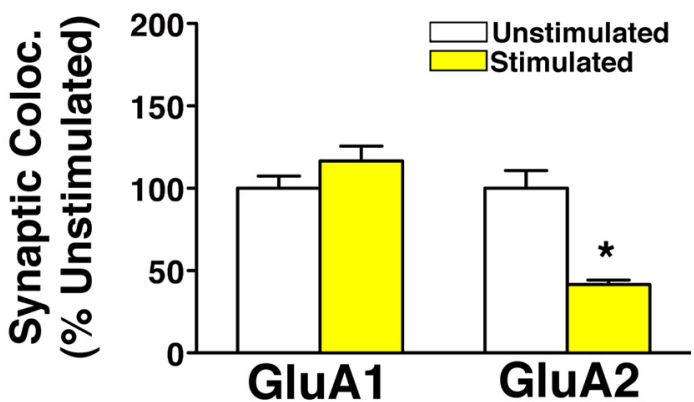

Figure 5. Ext'n of GluA1 and GluA2 on plasma membrane of ventral horn neurons after intermittent nociceptive stimulation below complete spinal cord injury. Large L4-L5 ventral horn neurons in were assessed for colocalization (yellow) of GluA1/2 (green) to synaptophysinpositive synapses (red) after nociceptive stimulation. Algorithmically selected single confocal planes of peak GluA1/synaptophysin colocalization for unstimulated $(\boldsymbol{A})$ and stimulated groups $(\boldsymbol{B})$, and GluA2/synaptophysin colocalization for unstimulated controls $(\boldsymbol{C})$ and stimulated groups $(\boldsymbol{D})$. $\boldsymbol{E}-\boldsymbol{H}, \mathrm{A} 2-\mu \mathrm{m}$-wide cutout of the confocal image containing somatic plasma membrane. $\boldsymbol{I}-\boldsymbol{L}$, Boxed plasma membrane fractions enlarged to illustrate representative differences in extrasynaptic (green) and synaptic (yellow) GluA1/2 puncta on motor neuron plasma membranes. $\boldsymbol{M}-\boldsymbol{P}$, Quantification of extrasynaptic GluA1/2 puncta and synaptic colocalization of subunit puncta with synaptophysin. $\boldsymbol{M}$, Extrasynaptic GluA1 was significantly increased 20 min after stimulation, whereas extrasynaptic GluA2 is significantly decreased (ANOVA, $* p<0.05$ ). $\mathbf{N}$, Synaptic colocalization of GluA1 and synaptophysin was also significantly increased $(* p<0.05$ ), whereas synaptic GluA2/synaptophysin colocalization is unaltered by stimulation. $\boldsymbol{O}$, Two hours after stimulation, extrasynaptic GluA1 expression is unchanged between stimulated and unstimulated groups, while extrasynaptic GluA2 remains significantly decreased in 
continued

response to stimulation ( $* p<0.05$ ). $\boldsymbol{P}$, Synaptic GluA1/synaptophysin colocalization is unchanged at $2 \mathrm{~h}$ poststimulation, but synaptic GluA2/synaptophysin colocalization is significantly decreased in response to stimulation (*p $<0.05$ ). Bars represent means for $124-146$ cells/group for GluA1, 105-154 cells per group for GluA2; $n=4$ subjects/per group, $N=16$ rats total. Error bars represent standard error of the mean.

from the brain, this sensorimotor training occurs in the spinal circuitry itself providing an assay of endogenous spinal cord plasticity (Buerger and Fennessy, 1970; Grau et al., 1998).

Our findings indicate that INS induces an acute modification of AMPAR function, producing an increase in $\mathrm{Ca}^{++}$permeability that we predict disrupts spinal sensorimotor learning. To explore this possibility, we assessed the impact of blocking CP-AMPARs using Naspm. NS administration impaired spinal learning in vehicle-treated subjects (Fig. 6B). Intrathecal delivery of Naspm immediately following INS produced a significant restoration of response duration over time (ANOVA, $F_{(1,29)}=1.64^{\mathrm{m}}, p<$ 0.05 ; Fig. $6 C$ ). This finding suggests that INS acutely undermines adaptive spinal plasticity through CP-AMPAR activity, and suggests that suppression of CP-AMPAR overdrive in the injured spinal cord may restore adaptive spinal synaptic modifications. Naspm has also been shown to be therapeutically effective when given $24 \mathrm{~h}$ after INS (Huie et al., 2012a).

\section{Discussion}

Our results demonstrate that peripheral nociceptive input below an acute complete SCl induces a form of AMPAmediated maladaptive synaptic plasticity that impairs future spinal cord training. Nociceptive stimulation directed GluA1 into ventral horn synaptoneurosomes and enhanced its PKC/CamKII site phosphorylation ( $p$-S831). Confocal imaging revealed time-dependent increases in GluA1 and decreased GluA2 on large spinal motor neurons, with GluA2 removal occurring first at extrasynaptic sites followed by synaptic removal $2 \mathrm{~h}$ later. These findings suggest that nociceptive stimulation persistently increases trafficking of GluA2-lacking (calcium-permeable) AMPARs to spinal synapses. The specific CP-AMPAR antagonist Naspm protected against INS-induced failure in a spinal sensorimotor learning task, indicating the necessity of CP-AMPAR activity for maladaptive spinal plasticity. Together, these findings reveal synaptic GluA2lacking AMPARs as mechanistic targets for restoring effective synaptic and behavioral plasticity in the injured spinal cord in vivo.

\section{A}

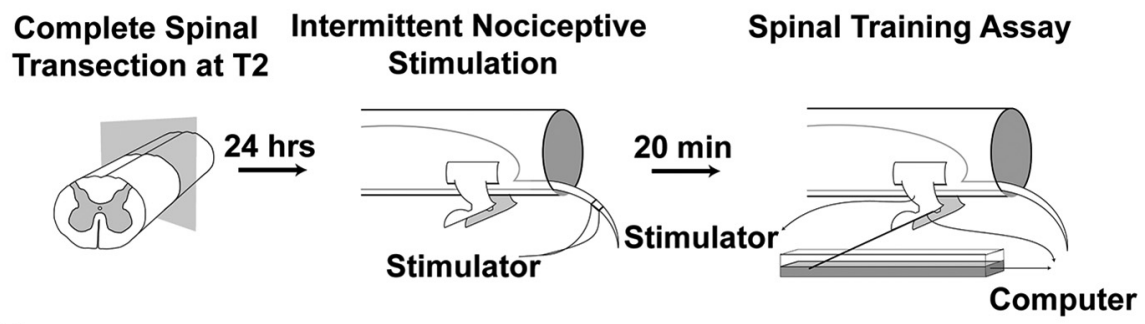

B

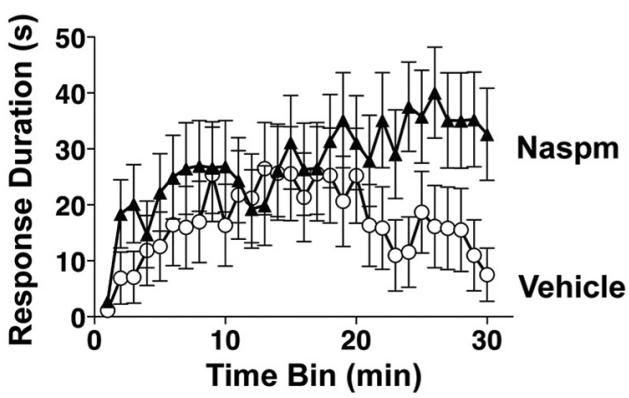

Figure 6. Effect of CP-AMPAR antagonist on impaired adaptive sensorimotor performance following intermittent nociceptive stimulation. $\boldsymbol{A}$, INS/spinal cord training paradigm. Rats with complete thoracic spinal transection received 6 min of INS to the tail followed by intrathecal administration of the CP-AMPAR antagonist Naspm (10 mm). Spinal instrumental training task began 20 min later. $\boldsymbol{B}$, Vehicle-treated subjects failed to exhibit a progressive increase in response duration over time, indicative of the INS-induced impairment in spinal adaptation. Naspm increased response duration over time, indicating that blocking CP-AMPAR activity protects against INS-induced maladaptive spinal plasticity. ANOVA revealed a significant increase in response duration over time in the Naspm-treated group compared to vehicle-treated animals, $n=12$ subjects/per group (repeated measures, $p<0.05$ ). Error bars represent standard error of the mean. 
Prior in vitro work has revealed that activity-dependent CP-AMPAR expression is regulated by rapid receptor trafficking to synaptic sites in two stages: AMPARs first insert at extrasynaptic sites and then traffic laterally into the postsynaptic density (Ehlers, 2000; Bredt and Nicoll, 2003). Our findings indicate that nociceptive stimulation in vivo engages a similar trafficking cycle for CP-AMPARs in the injured spinal cord (Fig. $5 \mathrm{M}, P$ ). Data from models of neuronal insult suggest that injury-induced activation of PKC can mobilize the AMPA-associated protein PICK1 to the postsynaptic density, where it binds specifically to GluA2 subunits and promotes the internalization of GluA2-containing AMPARs (Liu et al., 2006). Thus, GluA2lacking CP-AMPAR expression at postsynaptic sites is amplified though calcium-sensitive PKC activation, and may be sustained. Our finding that nociceptive stimulation increases $\mathrm{PKC} / \mathrm{CaMKII}$ site phosphorylation suggests a phenotypic switch to sustained CP-AMPAR expression that is in line with prior observations that PKC inhibitors can restore adaptive spinal cord plasticity in the face of nociceptive stimulation (Malmberg et al., 1997; Zeitz et al., 2001; Ferguson et al., 2008a; Asiedu et al., 2011; King et al., 2012).

The current study builds on previous findings that both nociceptive stimuli and spinal cord injury saturate glutamatergic neurotransmission, undermining adaptive spinal motor plasticity (Tillakaratne et al., 2002;
Chau et al., 2002; Ferguson et al., 2012b; Hoy et al., 2013). Prior work has also shown that both nociception and $\mathrm{SCl}$ generate inflammatory cytokines that amplify GluA2-lacking AMPAR tone (Ferguson et al., 2008b; Choi et al., 2010). INS below SCl has recently been shown to increase expression of the inflammatory cytokine tumor necrosis factor alpha (TNF $\alpha$ ) leading to long-term impairment in spinal learning (Huie et al., 2012a). Prior in vitro studies revealed that TNF $\alpha$ drives AMPAR currents, specifically by increasing synaptic GluA2-lacking CP-AMPAR expression (Beattie et al., 2002; Stellwagen et al., 2005; Leonoudakis et al., 2008). Further, TNF $\alpha$ also increases CP-AMPAR expression in vivo to induce rapid motor neuron death near the site of $\mathrm{SCl}$ (Ferguson et al., 2008b). Inhibiting either TNF $\alpha$ or CP-AMPAR activity (using Naspm) $24 \mathrm{~h}$ after INS restores the capacity for adaptive sensorimotor lumbar learning (Huie et al., 2012a), suggesting that CPAMPAR activity not only mediates the acute impact of nociceptive stimulation but also plays a key role in sustaining maladaptive plasticity over time. Naspm efficacy implies that INS does not impair lumbar-sacral learning simply because of enhanced spinal cord cell death through over-excitation. We tested this possibility by assessing a canonical apoptotic cell death marker (caspase 3), and a marker for calciumdependent cell death (calpain I). We complemented
A

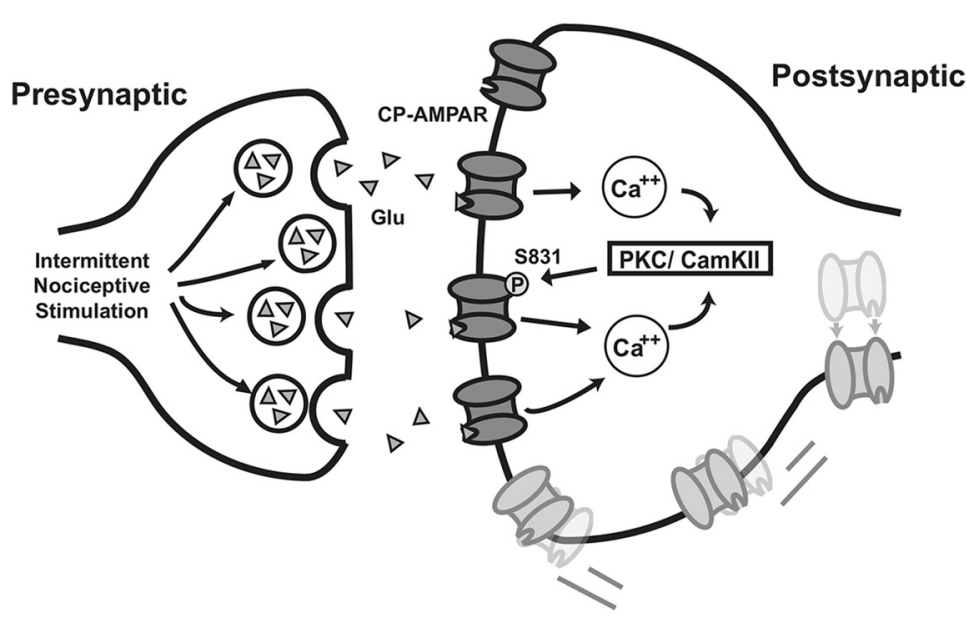

B
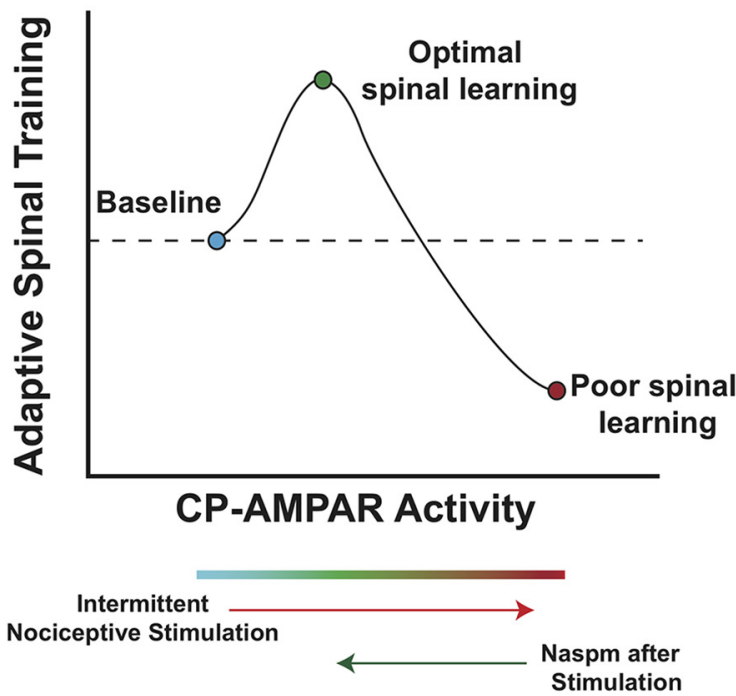

Figure 7. A, Theoretical pathway underlying INS-induced maladaptive plasticity. Following afferent intermittent nociceptive stimulation, increased glutamate release engages postsynaptic AMPA receptors. Calcium influx via CP-AMPARs activates the calcium detectors PKC and/or CamKI phosphorylating the serine 831 site on GluA1 AMPAR subunit. Serine 831 phosphorylation increases the open probability of AMPARs, creating a feedforward loop that leads to membrane insertion of extrasynaptic CP-AMPARs. These receptors are trafficked laterally to the synaptic membrane, further strengthening this excitatory connection. $\boldsymbol{B}$, Conceptual model of CP-AMPAR effects on spinal plasticity after SCI. CP-AMPAR activity critically shapes synaptic strength and use-dependent spinal cord plasticity after injury. Peripheral stimulation below the injury engages CP-AMPAR-mediated calcium influx, activating intracellular modulators of synaptic plasticity and strengthening excitatory tone to promote adaptive spinal training. However, CP-AMPARs are hyper-responsive to peripheral input (eg, limb positioning; skin stimulation) and are easily overdriven, resulting in synaptic saturation that overwhelms the capacity for adaptive spinal cord learning. As CP-AMPAR activity further increased, excitotoxicity and cell death may occur. Therapeutic intervention to decrease CP-AMPAR over-activity normalizes the balance of synaptic GluA1 and GluA2, and restores optimal adaptive plasticity. 
these markers with cFos and cJun, two indicators of acute cell activity that have been shown in cell death models to be closely associated with both glutamatergic excitotoxicity and apoptosis (Anderson et al., 1995; Hermann et al., 2001; Xu et al., 2005). Western blot analysis in the present paper showed that INS did not significantly increase expression of cFos, cJun, calpain I, or caspase 3. The lack of biochemical evidence for INS inducing cell death distal to injury indicates that INS drives a therapeutically reversible form of maladaptive spinal cord plasticity in the lumbar circuitry controlling movement. In contrast, work focusing on the lesion penumbra has found that INS enhances development of ongoing apoptosis and cell loss (Grau et al., 2004; Garraway et al., 2014). Although the impact of CP-AMPARs in this effect remains unclear, it is possible that Naspm could reduce excitotoxic components of secondary injury in addition to its impact on lumbar sensorimotor training, yielding dual therapeutic effects.

Based on theoretical and experimental evidence, we suggest a working model that INS alone first engages GluA2-lacking AMPARs resulting in calcium influx and activation of calcium detectors PKC and CamKII (Roche et al. 1996; Barria et al., 1997; Gómez-Pinilla et al., 2007; Ferguson et al., 2008a; Fig. 7A), which phosphorylate S831 to further strengthen synaptic GluA1 drive, but not GluA2 (Fig. 2). For vehicle-treated subjects, the training session following INS exposure further strengthens this maladaptive plasticity. In contrast, Naspm treatment resets the metaplastic state of the spinal cord, giving subjects the opportunity to exhibit an adaptive spinal learning response, initiating a second wave of AMPAR-mediated plasticity that involves a greater number of GluA2containing AMPARs. The data suggest that INS followed by a combined therapeutic effect of Naspm and spinal cord training, re-engages the PKC pathway, as evidenced by additional increases in both pS831 and GluA1 expression. Together, the data suggest that Naspm and adaptive training produce an optimal balance of AMPAR drive for spinal cord learning (Fig. 7B).

This model is consistent with the idea that both CPAMPAR over-activity and underactivity may be problematic. Naspm treatment in cultured hippocampal neurons may block the normal rebound of synaptic strength following tetrodotoxin administration, indicating that $\mathrm{CP}$ AMPARs are necessary for homeostatic plasticity in the brain (Hou et al., 2011). CP-AMPAR activity may produce a continuum of synaptic and behavioral effects, wherein moderate AMPAR-mediated calcium influx can be beneficial and necessary for adaptive plasticity (as in the stabilization of LTP in the brain, and in performance on the adaptive spinal sensorimotor task), but as CP-AMPAR activity increases in response to insult or nociceptive input, an excitatory saturation level is reached at which point spinal neurons lose the capacity to encode subtle simulation patterns, as in the adaptive spinal training task (Fig. 7B). Therapeutic interventions to restore homeostatic balance following injury or insult will likely be key in promoting the optimal glutamatergic regulation of adaptive plasticity. A growing body of evidence has shown that
AMPAR antagonists including Naspm restore neural function and suppress excitotoxic cell death in models of epilepsy, ischemia, neuropathic pain, opioid-induced hypersensitivity, and motor neuron diseases (Sorkin et al., 1999, 2001; Van Damme et al., 2003; Walters et al., 2005; Leonoudakis et al., 2008; Spaethling et al., 2008; Yin et al., 2012; Cabanero et al., 2013; Dias et al., 2013).

The current study contributes to these findings by presenting a possible cellular mechanism by which peripheral nociceptive input drives maladaptive spinal cord plasticity. The high incidence of polytrauma associated with SCl in the human population (Saboe et al., 1991; Sehkon and Fehlings, 2001; Wang et al., 2001; Hasler et al., 2011) highlights the need to understand the impact of nociceptive input in the injured spinal cord. Beyond clearlydefined peripheral injuries, growing evidence suggests that the injured spinal cord may also be sensitive to aberrant peripheral input, including limb immobilization and stretching (Caudle et al., 2011, 2015). Recent work in $\mathrm{SCl}$ patients demonstrates that c-fiber activation impacts retention of motor learning tasks (Bouffard et al., 2014). The present results provide a mechanism for these clinical findings, suggesting that CP-AMPARs represent a therapeutic target. The data presented in this study provide insight into maladaptive spinal plasticity in an isolated spinal system at acute time points following a complete $\mathrm{SCl}$. Future work on CP-AMPARs in other SCI models and at chronic time points will be invaluable for testing the therapeutic potential of targeted CP-AMPAR antagonism for mitigating maladaptive plasticity to promote functional recovery after spinal cord injury.

\section{REFERENCES}

Anderson AJ, Pike CJ, Cotman CW (1995) Differential induction of immediate early gene proteins in cultured neurons by betaamyloid ( $A$ beta): association of $c$-Jun with $A$ beta-induced apoptosis. J Neurochem 65:1487-1498. Medline

Asiedu MN, Tillu DV, Melemedjian OK, Shy A, Sanoja R, Bodell B, Ghosh S, Porreca F, Price TJ (2011) Spinal protein kinase M $\zeta$ underlies the maintenance mechanism of persistent nociceptive sensitization. J Neurosci 31:6646-6653. CrossRef Medline

Barria A, Muller D, Derkach V, Griffith LC, Soderling TR (1997) Regulatory phosphorylation of AMPA-type glutamate receptors by CaM-KII during long-term potentiation. Science 276:2042-2045. Medline

Baumbauer KM, Young EE, Hoy KC, Abood A, Joynes RL (2007) Administration of a Ca-super(2+)/calmodulin-dependent protein kinase II (CaMKII) inhibitor prevents the learning deficit observed in spinal rats after noncontingent shock administration. Behav Neurosci 121:570-578. CrossRef Medline

Beattie EC, Stellwagen D, Morishita W, Bresnahan JC, Ha BK, Von Zastrow M, Beattie MS, Malenka RC (2002) Control of synaptic strength by glial TNFalpha. Science 295:2282-2285. CrossRef Medline

Borgdorff AJ, Choquet D (2002) Regulation of AMPA receptor lateral movements. Nature 417:649-653. CrossRef Medline

Bouffard J, Bouyer LJ, Roy JS, Mercier C (2014) Tonic pain experienced during locomotor training impairs retention despite normal performance during acquisition. J Neurosci 34:9190-9195. CrossRef Medline

Bredt DS, Nicoll RA (2003) AMPA receptor trafficking at excitatory synapses. Neuron 40:361-379. Medline

Buerger AA, Fennessy A (1970) Learning of leg position in chronic spinal rats. Nature 225:751-752. Medline 
Cabanero D, Baker A, Zhou S, Hargett GL, Irie T, Xia Y, Beaudry H, Gendron L, Melyan Z, Carlton SM, Moron JA (2013) Pain after discontinuation of morphine treatment is associated with synaptic increase of GluA4-containing AMPAR in the dorsal horn of the spinal cord. Neuropsychopharmacology 38:1472-1484.

Caudle KL, Atkinson DA, Brown EH, Donaldson K, Seibt E, Chea T, Smith E, Chung K, Shum-Siu A, Cron CC, Magnuson DS (2015) Hindlimb stretching alters locomotor function after spinal cord injury in the adult rat. Neurorehabil Neural Repair 29:268-277. CrossRef

Caudle KL, Brown EH, Shum-Siu A, Burke DA, Magnuson TSG, Voor MJ, Magnuson DSK (2011) Hindlimb immobilization in a wheelchair alters functional recovery following contusive spinal cord injury in the adult rat. Neurorehabil Neural Repair 25:729-739. CrossRef

Chau C, Giroux N, Barbeau H, Jordan L, Rossignol S (2002) Effects of intrathecal glutamatergic drugs on locomotion: I. NMDA in short-term spinal cats. J Neurophysiol 88:3032-3045. CrossRef Medline

Choi JI, Svensson Cl, Koehrn FJ, Bhuskute A, Sorkin LS (2010) Peripheral inflammation induces tumor necrosis factor dependent AMPA receptor trafficking and Akt phosphorylation in spinal cord in addition to pain behavior. Pain 149:243-253. CrossRef Medline

Crown ED, Ferguson AR, Joynes RL, Grau JW (2002a) Instrumental learning within the spinal cord: II. Evidence for central mediation. Physiol Behav 77:259-267. Medline

Crown ED, Ferguson AR, Joynes RL, Grau JW (2002b) Instrumental learning within the spinal cord: IV. Induction and retention of the behavioral deficit observed after noncontingent shock. Behav Neurosci 116:1032-1051. Medline

Dias RB, Rombo DM, Ribeiro JA, Sebastião AM (2013) Ischemiainduced synaptic plasticity drives sustained expression of calcium-permeable AMPA receptors in the hippocampus. Neuropharmacology 65:114-122. CrossRef Medline

Drdla-Schutting R, Benrath J, Wunderbaldinger G, Sandkühler J (2012) Erasure of a spinal memory trace of pain by a brief, highdose opioid administration. Science 335:235-238. CrossRef Medline

Ehlers MD (2000) Reinsertion or degradation of AMPA receptors determined by activity-dependent endocytic sorting. Neuron 28: 511-525. Medline

Ferguson AR, Crown ED, Grau JW (2006) Nociceptive plasticity inhibits adaptive learning in the spinal cord. Neuroscience 141: 421-431. CrossRef Medline

Ferguson AR, Bolding KA, Huie JR, Hook MA, Santillano DR, Miranda RC, Grau JW (2008a) Group I metabotropic glutamate receptors control metaplasticity of spinal cord learning through a protein kinase C-dependent mechanism. J Neurosci 28:1193911949. CrossRef Medline

Ferguson AR, Christensen RN, Gensel JC, Miller BA, Sun F, Beattie EC, Bresnahan JC, Beattie MS (2008b) Cell death after spinal cord injury is exacerbated by rapid TNF alpha-induced trafficking of GluR2-lacking AMPARs to the plasma membrane. J Neurosci 28:11391-11400. CrossRef Medline

Ferguson AR, Huie JR, Crown ED, Grau JW (2012a) Central nociceptive sensitization vs. spinal cord training: opposing forms of plasticity that dictate function after complete spinal cord injury. Front Physiol 3:396. CrossRef Medline

Ferguson AR, Huie JR, Crown ED, Baumbauer KM, Hook MA, Garraway SM, Lee KH, Hoy KC, Grau JW (2012b) Maladaptive spinal plasticity opposes spinal learning and recovery in spinal cord injury. Front Physiol 3:399.

Galan A, Laird J, Cervero F (2004) In vivo recruitment by painful stimuli of AMPA receptor subunits to the plasma membrane of spinal cord neurons. Pain 112:315-323. CrossRef Medline

Garcia-Bereguiain MA, Gonzalez-Islas C, Lindsly C, Butler E, Hill AW, Wenner $P$ (2013) In vivo synaptic scaling is mediated by GluA2lacking AMPA receptors in the embryonic spinal cord. J Neurosci 33:6791-6799. CrossRef Medline
Garraway SM, Turtle JD, Huie JR, Lee KH, Hook MA, Woller SA, Grau JW (2011) Intermittent noxious stimulation following spinal cord contusion injury impairs locomotor recovery and reduces spinal brain-derived neurotrophic factor-tropomyosin-receptor kinase signaling in adult rats. Neuroscience 199:86-102. CrossRef Medline

Garraway SM, Woller SA, Huie JR, Hartman JJ, Hook MA, Miranda RC, Huang Y-J, Ferguson AR, Grau JW (2014) Peripheral noxious stimulation reduces withdrawal threshold to mechanical stimuli after spinal cord injury: role of tumor necrosis factor alpha and apoptosis. Pain 155:2344-2359. CrossRef Medline

Gómez-Pinilla F, Huie JR, Ying Z, Ferguson AR, Crown ED, Baumbauer KM, Edgerton VR, Grau JW (2007) BDNF and learning: Evidence that instrumental training promotes learning within the spinal cord by up-regulating BDNF expression. Neuroscience 148: 893-906. CrossRef Medline

Grau JW, Barstow DG, Joynes RL (1998) Instrumental learning within the spinal cord: I. Behavioral properties. Behav Neurosci 112: 1366-1386. Medline

Grau JW, Crown ED, Ferguson AR, Washburn SN, Hook MA, Miranda $\mathrm{RC}$ (2006) Instrumental learning within the spinal cord: underlying mechanisms and implications for recovery after injury. Behav Cogn Neurosci Rev 5:191-239. CrossRef Medline

Grau JW, Washburn SN, Hook MA, Ferguson AR, Crown ED, Garcia G, Bolding KA, Miranda RC (2004) Uncontrollable stimulation undermines recovery after spinal cord injury. J Neurotrauma 21: 1795-1817. CrossRef Medline

Grau JW, Huie R, Garraway SM, Hook MA, Crown ED, Baumbauer KM, Lee KH, Hoy KC, Ferguson AR (2012) Impact of behavioral control on the processing of nociceptive stimulation. Front Physiol 3:262. CrossRef

Hartmann B, Ahmadi S, Heppenstall PA, Lewin GR, Schott C, Borchardt T, Seeburg PH, Zeilhofer HU, Sprengel R, Kuner R (2004) The AMPA receptor subunits GluR-A and GluR-B reciprocally modulate spinal synaptic plasticity and inflammatory pain. Neuron 44:637-650. CrossRef Medline

Hasler RM, Exadaktylos AK, Bouamra O, Benneker LM, Clancy M, Sieber R, Zimmermann H, Lecky F (2011) Epidemiology and predictors of spinal injury in adult major trauma patients: European cohort study. Eur Spine J 20:2174-2180. CrossRef Medline

Hermann GE, Rogers RC, Bresnahan JC, Beattie MS (2001) Tumor necrosis factor-alpha induces cFOS and strongly potentiates glutamate-mediated cell death in the rat spinal cord. Neurobiol Dis 8:590-599. CrossRef Medline

Hollmann M, Hartley M, Heinemann S (1991) Ca2+ permeability of KA-AMPA-gated glutamate receptor channels depends on subunit composition. Science 252:851-853. Medline

Hook MA, Huie JR, Grau JW (2008) Peripheral inflammation undermines the plasticity of the isolated spinal cord. Behav Neurosci 122:233-249. CrossRef Medline

Hou Q, Gilbert J, Man HY (2011) Homeostatic regulation of AMPA receptor trafficking and degradation by light-controlled singlesynaptic activation. Neuron 72:806-818. CrossRef Medline

Hoy KC, Huie JR, Grau JW (2013) AMPA receptor mediated behavioral plasticity in the isolated rat spinal cord. Behav Brain Res 236:319-326. CrossRef Medline

Huie JR, Baumbauer KM, Lee KH, Bresnahan JC, Beattie MS, Ferguson AR, Grau JW (2012a) Glial tumor necrosis factor alpha $(\mathrm{TNF} \alpha)$ generates metaplastic inhibition of spinal learning. PLoS One 7:e39751. CrossRef Medline

Huie JR, Garraway SM, Baumbauer KM, Hoy KC Jr, Beas BS, Montgomery KS, Bizon JL, Grau JW (2012b) Brain-derived neurotrophic factor promotes adaptive plasticity within the spinal cord and mediates the beneficial effects of controllable stimulation. Neuroscience 200C:74-90.

Ikeda $\mathrm{H}$ (2006) Synaptic amplifier of inflammatory pain in the spinal dorsal horn. Science 312:1659-1662. CrossRef Medline

Ji RR, Kohno T, Moore KA, Woolf CJ (2003) Central sensitization and LTP: do pain and memory share similar mechanisms? Trends Neurosci 26:696-705. CrossRef Medline 
King T, Qu C, Okun A, Melemedjian OK, Mandell EK, Maskaykina IY, Navratilova E, Dussor GO, Ghosh S, Price TJ, Porreca F (2012) Contribution of PKM $\zeta$-dependent and independent amplification to components of experimental neuropathic pain. Pain 153:12631273. CrossRef Medline

Kuner R, Groom AJ, Bresink I, Kornau HC, Stefovska V, Müller G, Hartmann B, Tschauner K, Waibel S, Ludolph AC, Ikonomidou C, Seeburg PH, Turski L (2005) Late-onset motoneuron disease caused by a functionally modified AMPA receptor subunit. Proc Natl Acad Sci U S A 102:5826-5831. CrossRef Medline

Landis SC, Amara SG, Asadullah K, Austin CP, Blumenstein R, Bradley EW, Crystal RG, Darnell RB, Ferrante RJ, Fillit H, Finkelstein R, Fisher M, Gendelman HE, Golub RM, Goudreau JL, Gross RA, Gubitz AK, Hesterlee SE, Howells DW, Huguenard J, et al. (2012) A call for transparent reporting to optimize the predictive value of preclinical research. Nature 490:187-191. CrossRef Medline

Lee HK, Barbarosie M, Kameyama K, Bear MF, Huganir RL (2000) Regulation of distinct AMPA receptor phosphorylation sites during bidirectional synaptic plasticity. Nature 405:955-959. CrossRef Medline

Leonoudakis D, Zhao P, Beattie EC (2008) Rapid tumor necrosis factor alpha-induced exocytosis of glutamate receptor 2-lacking AMPA receptors to extrasynaptic plasma membrane potentiates excitotoxicity. J Neurosci 28:2119-2130. CrossRef Medline

Liu B, Liao M, Mielke JG, Ning K, Chen Y, Li L, El-Hayek YH, Gomez E, Zukin RS, Fehlings MG, Wan Q (2006) Ischemic insults direct glutamate receptor subunit 2-lacking AMPA receptors to synaptic sites. J Neurosci 26:5309-5319. CrossRef Medline

Malmberg AB, Chen C, Tonegawa S, Basbaum Al (1997) Preserved acute pain and reduced neuropathic pain in mice lacking PKCgamma. Science 278:279-283. Medline

Man HY (2011) GluA2-lacking, calcium-permeable AMPA receptors: inducers of plasticity? Curr Opin Neurobiol 21:291-298. CrossRef Medline

Matsuda S, Mikawa S, Hirai H (1999) Phosphorylation of serine-880 in GluR2 by protein kinase $C$ prevents its $C$ terminus from binding with glutamate receptor-interacting protein. J Neurochem 73: 1765-1768. Medline

Oh MC, Kim JM, Safaee M, Kaur G, Sun MZ, Kaur R, Celli A, Mauro TM, Parsa AT (2012) Overexpression of calcium-permeable glutamate receptors in glioblastoma derived brain tumor initiating cells. PLoS One 7:e47846. CrossRef Medline

Park M, Penick EC, Edwards JG, Kauer JA, Ehlers MD (2004) Recycling endosomes supply AMPA receptors for LTP. Science 305: 1972-1975. CrossRef Medline

Roche KW, O'Brien RJ, Mammen AL, Bernhardt J, Huganir RL (1996) Characterization of multiple phosphorylation sites on the AMPA receptor GluR1 subunit. Neuron 16:1179-1188. Medline

Ruscheweyh R, Wilder-Smith O, Drdla R, Liu XG, Sandkühler J (2011) Long-term potentiation in spinal nociceptive pathways as a novel target for pain therapy. Molecular Pain 7:20. CrossRef Medline

Saboe LA, Reid DC, Davis LA, Warren SA, Grace MG (1991) Spine trauma and associated injuries. J Trauma 31:43-48. Medline

Sandkühler J, Liu XG (1998) Induction of long-term potentiation at spinal synapses by noxious stimulation or nerve injury. Eur $\mathrm{J}$ Neurosci 10:2476-2480. Medline
Sandkühler J (2009) Models and mechanisms of hyperalgesia and allodynia. Physiol Rev 89:707-758. CrossRef

Sekhon L, Fehlings MG (2001) Epidemiology, demographics, and pathophysiology of acute spinal cord injury. Spine 26:S2-S12. Medline

Sorkin LS, Yaksh TL, Doom CM (1999) Mechanical allodynia in rats is blocked by a $\mathrm{Ca} 2+$ permeable AMPA receptor antagonist. Neuroreport 10:3523-3526. Medline

Sorkin LS, Yaksh TL, Doom CM (2001) Pain models display differential sensitivity to $\mathrm{Ca} 2+-$ permeable non-NMDA glutamate receptor antagonists. Anesthesiology 95:965-973. Medline

Spaethling J, Le L, Meaney DF (2012) NMDA receptor mediated phosphorylation of GluR1 subunits contributes to the appearance of calcium-permeable AMPA receptors after mechanical stretch injury. Neurobiol Dis 46:646-654. CrossRef Medline

Spaethling JM, Klein DM, Singh P, Meaney DF (2008) Calciumpermeable AMPA receptors appear in cortical neurons after traumatic mechanical injury and contribute to neuronal fate. J Neurotrauma 25:1207-1216. CrossRef Medline

Stellwagen D, Beattie EC, Seo JY, Malenka RC (2005) Differential regulation of AMPA receptor and GABA receptor trafficking by tumor necrosis factor-alpha. J Neurosci 25:3219-3228. CrossRef Medline

Stück ED, Christensen RN, Huie JR, Tovar CA, Miller BA, Nout YS, Bresnahan JC, Beattie MS, Ferguson AR (2012) Tumor necrosis factor alpha mediates $\mathrm{GABA}(\mathrm{A})$ receptor trafficking to the plasma membrane of spinal cord neurons in vivo. Neural Plast 2012: 261345. CrossRef Medline

Tillakaratne NJ, de Leon RD, Hoang TX, Roy RR, Edgerton VR, Tobin AJ (2002) Use-dependent modulation of inhibitory capacity in the feline lumbar spinal cord. J Neurosci 22:3130-3143. Medline Medline

Van Damme P, Leyssen M, Callewaert G, Robberecht W, Van Den Bosch L (2003) The AMPA receptor antagonist NBQX prolongs survival in a transgenic mouse model of amyotrophic lateral sclerosis. Neurosci Lett 343:81-84. Medline

von Lewinski F, Keller BU (2005) Ca2+, mitochondria and selective motoneuron vulnerability: implications for ALS. Trends Neurosci 28:494-500. CrossRef Medline

Walters MR, Kaste M, Lees KR, Diener HC, Hommel M, De Keyser J, Steiner H, Versavel M (2005) The AMPA antagonist ZK 200775 in patients with acute ischaemic stroke: a double-blind, multicentre, placebo-controlled safety and tolerability study. Cerebrovasc Dis 20:304-309. CrossRef Medline

Wang CM, Chen Y, DeVivo MJ, Huang CT (2001) Epidemiology of extraspinal fractures associated with acute spinal cord injury. Spinal Cord 39:589-594. CrossRef Medline

Xu W, Chi L, Xu R, Ke Y, Luo C, Cai J, Quu M, Gozal D, Liu R (2005) Increased production of reactive oxygen species contributes to motor neuron death in a compression mouse model of spinal cord injury. Spinal Cord 43:204-213. CrossRef

Yin HZ, Hsu Cl, Yu S, Rao SD, Sorkin LS, Weiss JH (2012) TNF- $a$ triggers rapid membrane insertion of $\mathrm{Ca}(2+)$ permeable AMPA receptors into adult motor neurons and enhances their susceptibility to slow excitotoxic injury. Exp Neurol 238:93-102. CrossRef Medline

Zeitz KP, Malmberg AB, Gilbert H, Basbaum Al (2001) Reduced development of tolerance to the analgesic effects of morphine and clonidine in PKC gamma mutant mice. Pain 94:245-253. Medline 